\title{
Anopheles stephensi p38 MAPK signaling regulates innate immunity and bioenergetics during Plasmodium falciparum infection
}

Bo Wang ${ }^{1}$, Nazzy Pakpour ${ }^{1}$, Eleonora Napoli², Anna Drexler ${ }^{1}$, Elizabeth K. K. Glennon ${ }^{1}$, Win Surachetpong ${ }^{1}$, Kong Cheung ${ }^{1}$, Alejandro Aguirre', John M. Klyver ${ }^{1}$, Edwin E. Lewis ${ }^{3}$, Richard Eigenheer ${ }^{4}$, Brett S. Phinney ${ }^{4}$, Cecilia Giulivi ${ }^{2,5}$ and Shirley Luckhart ${ }^{1 *}$

\begin{abstract}
Background: Fruit flies and mammals protect themselves against infection by mounting immune and metabolic responses that must be balanced against the metabolic needs of the pathogens. In this context, p38 mitogen-activated protein kinase (MAPK)-dependent signaling is critical to regulating both innate immunity and metabolism during infection. Accordingly, we asked to what extent the Asian malaria mosquito Anopheles stephensi utilizes p38 MAPK signaling during infection with the human malaria parasite Plasmodium falciparum.

Methods: A. stephensi p38 MAPK (AsP38 MAPK) was identified and patterns of signaling in vitro and in vivo (midgut) were analyzed using phospho-specific antibodies and small molecule inhibitors. Functional effects of AsP38 MAPK inhibition were assessed using $P$. falciparum infection, quantitative real-time PCR, assays for reactive oxygen species and survivorship under oxidative stress, proteomics, and biochemical analyses.

Results: The genome of A. stephensi encodes a single p38 MAPK that is activated in the midgut in response to parasite infection. Inhibition of AsP38 MAPK signaling significantly reduced P. falciparum sporogonic development. This phenotype was associated with AsP38 MAPK regulation of mitochondrial physiology and stress responses in the midgut epithelium, a tissue critical for parasite development. Specifically, inhibition of AsP38 MAPK resulted in reduction in mosquito protein synthesis machinery, a shift in glucose metabolism, reduced mitochondrial metabolism, enhanced production of mitochondrial reactive oxygen species, induction of an array of anti-parasite effector genes, and decreased resistance to oxidative stress-mediated damage. Hence, P. falciparum-induced activation of AsP38 MAPK in the midgut facilitates parasite infection through a combination of reduced anti-parasite immune defenses and enhanced host protein synthesis and bioenergetics to minimize the impact of infection on the host and to maximize parasite survival, and ultimately, transmission.

Conclusions: These observations suggest that, as in mammals, innate immunity and mitochondrial responses are integrated in mosquitoes and that AsP38 MAPK-dependent signaling facilitates mosquito survival during parasite infection, a fact that may attest to the relatively longer evolutionary relationship of these parasites with their invertebrate compared to their vertebrate hosts. On a practical level, improved understanding of the balances and trade-offs between resistance and metabolism could be leveraged to generate fit, resistant mosquitoes for malaria control.
\end{abstract}

Keywords: Malaria, Mitochondria, Innate immunity, Mitogen-activated protein kinase, MAPK, p38, Plasmodium, Anopheles, OXPHOS

\footnotetext{
* Correspondence: sluckhart@ucdavis.edu

'Department of Medical Microbiology and Immunology, School of Medicine, University of California Davis, 3437 Tupper Hall, One Shields Avenue, Davis, CA 95616, USA

Full list of author information is available at the end of the article
} 


\section{Background}

The biological complexity of the malaria parasite life cycle has made it an elusive target for drug and vaccine development. This has led to the re-emergence and further spread of this disease, with over 250 million new cases of malaria occurring annually [1]. The malaria parasite life cycle involves development and transmission by Anopheles mosquitoes. Plasmodium development in Anopheles begins with ingestion by the mosquito of blood containing male and female gametocytes; these fuse within minutes of ingestion to form mobile ookinetes that penetrate the midgut epithelium 24-36 h later and rapidly transform into vegetative oocysts. After growth and development for 10-12 days (the extrinsic incubation period or EIP), hundreds to thousands of sporozoites are released from each oocyst into the hemolymph, the open circulatory system of the mosquito. These sporozoites invade the salivary glands, where they are released into the saliva and injected into a human host during subsequent blood feeding. As parasites undergo these developmental transitions, they are simultaneously exposed to physical, chemical, and immune barriers of the mosquito that act to limit infection $[2,3]$. Chemical barriers of the midgut, such as increased reactive nitrogen and oxygen species (RNOS) can kill parasites directly in the gut lumen, preventing contact between parasites and the epithelium [4-9]. Additional immune defenses are activated when parasites encounter the midgut epithelium and include the production of immune effectors such as TEP1 $[10,11]$, APL1 $[12,11,13]$, LRIM1 [14, 11], and LRRD7 [15], which together function to further limit parasite development. For successful infection, ookinetes must traverse the midgut by migration through or between midgut epithelial cells [16]; therefore, the integrity of the physical barrier of the midgut epithelial can also limit parasite development [7].

Mitogen-activated protein kinases (MAPKs) are serine/ threonine protein kinases that regulate a variety of cellular processes. The three main families of MAPKs are the extracellular signal-regulated kinases (ERKs), c-Jun Nterminal kinases (JNKs) and p38 MAPKs (reviewed in [17]). P38 MAPK is highly conserved and critical to innate immune responses in a variety of organisms [18-21]. In mammals, four p38 MAPK isoforms can be activated by bacterial, viral, and parasitic stimuli (reviewed in [22]). Caenorhabditis elegans has a single p38 MAPK ortholog (PMK-1) that regulates antimicrobial peptide expression (reviewed in [21]). In Drosophila melanogaster, two p38 MAPK orthologs (p38a and p38b) participate in the host immune response to bacterial and fungal stimuli [19], while Aedes mosquitoes encode a single p38 MAPK that is involved in innate immune responses to bacterial pathogens [23-25]. The midgut/intestine is a central tissue for p38 MAPK regulation in both D. melanogaster [26-28] and in C. elegans $[29,30]$, where this pathway regulates gut homeostasis and immunity. The Anopheles gambiae [31] and Anopheles stephensi genomes each encode a single p38 MAPK, described herein, with associated pathway signaling proteins [31]. Based on collective observations from other species and the conservation of this pathway, we hypothesized that p38 MAPK signaling contributes to regulation of the response of Anopheles mosquitoes to midgut development of Plasmodium parasites [32].

In addition to regulating the innate immune response, p38 MAPK signaling also plays an important role in the coordination of cellular stress responses [33, 34]. For example, members of the MAPK family, including p38 MAPK, can be activated by reactive oxygen species (ROS) $[31,35,36]$. While high levels of ROS can be detrimental to the host and invading organisms, moderate levels of ROS can act as signaling mediators in a number of biological processes including both innate and adaptive immunity [37-39]. In D. melanogaster, ROS-activated p38 MAPK induces the expression of the antioxidant manganese superoxide dismutase (SOD2) [38], while in mammals activation of p38 MAPK by ROS increases expression of the antioxidants catalase and SOD [40]. In these organisms, the production of antioxidants acts to attenuate the molecular damage and cell death that high levels of ROS can cause and ultimately feeds back to inhibit p38 MAPK activity. However, in mosquitoes, high levels of ROS are not only detrimental to the host but also to invading organisms such as malaria parasites [8, 41, 42], indicating that a p38 MAPK-induced decrease in ROS could be beneficial to both host survival and parasite development. In addition, a number of studies have shown that ROS and NO can regulate activity of inflammatory signaling pathways including those that are dependent on nuclear factor (NF)-кB [43, 44], suggesting that p38 MAPK signaling could also alter ROS-dependent induction of NF-kBdependent anti-malarial immune genes. Although we have previously shown that $\mathrm{p} 38$ MAPK can be activated by ROS in Anopheles midgut [31,35], the downstream effects of this activation on mosquito biology remain unclear.

Activation of p38 MAPK has also been associated with increased protein translation via enhanced phosphorylation of MAPK-activated kinase 2 (MK2), which can increase mRNA stability and translation. In particular, MK2 abrogates mRNA instability caused by the presence of AU-rich elements in the 3'-untranslated region of transcripts [45-48]. In addition, p38 MAPK activation increases peroxisome proliferator-activated receptor gamma coactivator- $1 \alpha(\mathrm{PGC}-1 \alpha)$ phosphorylation and PGC-1 $\beta$ expression $[48,49]$. PGC- $1 \alpha$ and PGC- $1 \beta$ belong to a family of coactivator proteins that are highly responsive to environmental cues, such as temperature and nutritional status, and that regulate the maintenance of glucose, lipid, and energy (reviewed in [49]). In mammals, PGC-1 $\alpha$ and 
PGC-1 $\beta$ regulate mitochondrial biogenesis and oxidative metabolism in a tissue- and trigger-specific manner through coactivation of the peroxisome proliferatoractivated receptors $[50,51]$, estrogen-related receptors [52], and nuclear respiratory factors [53]. In addition to these functions, PGC- $1 \alpha$ and PGC- $1 \beta$ regulate important aspects of metabolism and immunity. For example, PGC- $1 \alpha$, under starvation, exercise or adaptive thermogenesis, is known to drive expression of the gluconeogenetic enzymes phosphoenolpyruvate carboxykinase (PEPCK) and glucose-6-phosphatase (G6Pase), while PGC-1 $\beta$ enhances fatty acid oxidation and adrenergicindependent mitochondrial biogenesis, principally through the activation of pyruvate kinase $(\mathrm{PK})$ and the hexokinase glucokinase [54-57]. In addition, PGC-1 $\beta$ has been recognized as a critical regulator of mammalian immune function [58]. In particular, interferon (IFN)- $\gamma$-induced activation of macrophage mitochondrial ROS for host defense is regulated via activation of PGC- $1 \beta$ by the IFN- $\gamma$ signal transducer and activator of transcription (STAT)-1 signaling cascade [59].

In D. melanogaster, the single PGC-1 ortholog Spargel controls mitochondrial biogenesis and is a downstream effector of the insulin-target of rapamycin (TOR) nutrient sensing signaling cascade, suggesting that PGC-1 control of energy homeostasis and nutritional status are conserved from insects to mammals [60-62]. Our previous studies have implicated coordinated control of insulin/insulin-like growth factor signaling (IIS)-dependent mitochondrial biogenesis with inflammatory ROS and NO synthesis and resistance to P. falciparum infection in A. stephensi [63]. The full spectrum of regulatory pathways, however, in the fly - and in anopheline mosquitoes as well - that integrate mitochondrial function and immunity is unknown. Collectively, our work and published observations suggested that a subset of these functions could be integrated by p38 MAPK signaling during the mosquito host response to infection. In support of this hypothesis, we show here that P. falciparum infection of A. stephensi enhances p38 MAPK activation in the midgut within $30 \mathrm{~min}$ of blood feeding. Pharmacological inhibition of A. stephensi p38 (AsP38) MAPK signaling pathway yielded a significant decrease in P. falciparum development in the mosquito midgut. This was most likely due to increased ROS and enhanced immune gene expression observed within the first $24 \mathrm{~h}$ following inhibition of AsP38 MAPK signaling. Increased ROS levels can directly kill parasites and signal anti-malarial immune gene expression. Concurrently, AsP38 MAPK inhibition significantly reduced transcript levels of PGC-1 as well as expression of mitochondrial proteins related to ATP production, protein translation, and antioxidants, including mitochondrial SOD (SOD2). Functionally, inhibition of AsP38 MAPK enhanced mosquito sensitivity to paraquat-induced oxidative stress and precipitated a shift to glycolytic metabolism even in the absence of parasite infection. Collectively these data suggest that AsP38 MAPK-dependent repression of immunity to $P$. falciparum is associated with enhanced mitochondrial biogenesis, oxidative phosphorylation (OXPHOS), antioxidant biosynthesis, and protein translation, which may help the mosquito to survive parasite infection.

\section{Methods}

\section{Identification of $A$. stephensi p38 MAPK}

Anopheles gambiae p38 MAPK amino acid sequence [31] was used as a query to identify the homologous fulllength coding sequence of the AsP38 MAPK sequence in the February 2014 A. stephensi Indian strain assembly by Basic Local Alignment Search Tool (BLAST) [64]. The region with the best match and 1 kilobase of flanking sequence were retrieved. Encoded domain sequences were confirmed by manual protein sequence alignments. Putative translational start site of the assembled AsP38 MAPK encoding gene was predicted using the ExPASy translate tool (web.expasy.org/translate/) and adherence to Kozak consensus [65].

RNA was isolated from 30 midguts of non-blood fed, female $A$. stephensi mosquitoes using TriZOL reagent (Invitrogen) for RNA extraction. Contaminating DNA was removed from the RNA samples using Turbo DNA-free (Ambion) and cDNA was synthesized using the SuperScript ${ }^{\circ}$ III First-Strand Synthesis System (Invitrogen). Sample cDNAs were used to perform PCR using high fidelity AccuPrime Taq DNA Polymerase (Invitrogen). Primers were designed based on AsP38 MAPK sequence using Primer Express software (Applied Biosystems). The following AsP38 MAPK specific primers were used: AsP38 MAPK forward 5'-GTGTGTCCATCTGTTCCGTA-3' and reverse 5'-TTACGCCTGCGGTTC- 3' for both cloning and sequencing.

\section{Cell culture and luciferase reporter assays}

ASE cells were maintained as previously described [35]. For AsP38 MAPK phosphorylation studies, ASE cells were either treated with $1 \mu \mathrm{g} / \mathrm{ml}$ LPS alone or pretreated with $10 \mu \mathrm{M}$ BIRB796, $10 \mu \mathrm{M}$ SB203580, or an equivalent volume of DMSO as a control for $2 \mathrm{~h}$. Luciferase reporter assays were performed using the Defensin1, Cecropin1, and Gambicin promoter-reporter plasmids as previously described [35]. At $24 \mathrm{~h}$ post-transfection, cells were treated with $100 \mu \mathrm{g} / \mathrm{ml}$ LPS (Sigma-Aldrich) or $2 \mu \mathrm{g} / \mathrm{ml}$ peptidoglycan (PGN, Escherichia coli K12) with 0.1-10 $\mu \mathrm{M}$ BIRB796 or an equivalent volume of DMSO as a control. Luciferase activity was measured $24 \mathrm{~h}$ post-LPS or PGN treatment with the Dual-Glo system (Promega). 


\section{Immunoblotting}

Protein extracts were prepared, separated, and transferred to membranes as previously described [66]. Membranes were blocked in $5 \%$ nonfat dry milk (w/v) in Tris-buffered saline ( $\mathrm{pH} 7.0)$ containing $0.1 \%$ Triton100 (TBS-T) for $1 \mathrm{~h}$ at room temperature. Membranes were incubated at $4{ }^{\circ} \mathrm{C}$ overnight with the following: 1:2,500 rabbit anti-phospho-p38 MAPK antibody (Cayman Chemical), 1:2,000 rabbit anti-phospho-MK2 antibody (Abgent), or with 1:10,000 rabbit anti-GAPDH antibody (Abcam) in $5 \%$ non-fat dry milk in TBS-T. Anti-phosphop38 MAPK antibody and anti-phospho-MK2 antibody were raised against mammalian proteins; peptide sequences used to produce these monoclonal antibodies have greater than $90 \%$ identity to their counterparts in A. stephensi. Membranes were washed three times for 5 min each in $1 \mathrm{X}$ TBS-T and incubated with a 1:20,000 dilution of HRPconjugated goat anti-rabbit (Fab')2 fragment (Cell Signaling Technology) at $4{ }^{\circ} \mathrm{C}$ overnight. To reveal antibody-bound proteins, membranes were incubated with SuperSignal West Dura chemiluminescent reagent for $5 \mathrm{~min}$ and visualized using the Kodak Image Station 4000MM Pro and Carestream Molecular Imaging software (Carestream Health). Levels of phospho-proteins in each treatment were first normalized to total protein levels as determined by GAPDH and then to the appropriate control group.

\section{Mosquito rearing and experimental treatments}

A. stephensi Liston (Indian strain) were reared and maintained at $27{ }^{\circ} \mathrm{C}$ and $80 \%$ humidity. All mosquito rearing and feeding protocols were approved and in accordance with regulatory guidelines and standards set by the Institutional Animal Care and Use Committee of the University of California, Davis. For experimental treatments, laboratory reared 3-5 day old female mosquitoes were kept on water overnight and then allowed to feed for $30 \mathrm{~min}$ on reconstituted human blood meals provided through a Hemotek Insect Feeding System (Discovery Workshops).

\section{$P$. falciparum culture and mosquito infection}

For mosquito infection, cultures of $P$. falciparum strain NF54 MCB (obtained from Sanaria, www.sanaria.com) were grown as previously described [66]. Mosquitoes were allowed to feed on day 15 mature gametocyte cultures diluted with human RBCs and heat-inactivated human serum with or without the p38 MAPK inhibitors 0.1-10 $\mu \mathrm{M}$ SB203580 or $10 \mu \mathrm{M}$ BIRB796. All treatments were added to the diluted $P$. falciparum culture immediately prior to blood feeding. Protocols involving the culture and handling of $P$. falciparum for mosquito feeding were approved and in accordance with regulatory guidelines and standards set by the Biological Safety Administrative Advisory Committee of the University of California, Davis.
After 10 days, midguts from 50 mosquitoes with fully developed eggs (to confirm complete engorgement) from each group were dissected in PBS and stained with $0.1 \%$ mercurochrome for direct counting of $P$. falciparum oocysts. Means of oocysts per midgut in each treatment group were calculated from all dissected mosquitoes, excluding zeros for mosquitoes that contained no oocysts.

\section{$P$. falciparum growth assays}

Aliquots of $P$. falciparum NF54 culture were synchronized $48 \mathrm{~h}$ prior to the assay as described [67] and then plated in 96 well flat bottom plates in complete RPMI 1640 with HEPES, hypoxanthine and $10 \%$ heat inactivated human serum. Parasites were treated with 1 or $10 \mu \mathrm{M}$ SB203580 or BIRB796 or with an equivalent volume of DMSO diluent for $48 \mathrm{~h}$ in a candle jar in a $37{ }^{\circ} \mathrm{C}$ incubator. Infected RBCs were quantified as previously described [66].

\section{Quantitative real-time PCR of mRNA transcripts}

For immune gene expression assays 3-5 day old $A$. stephensi were fed a blood meal containing freezethawed $P$. falciparum products (FTPP, preparation described in [68]) supplemented with $10 \mu \mathrm{M}$ BIRB796 or an identical FTPP blood meal supplemented with an equivalent volume of DMSO diluent as a control. A total of 30 midguts at each time point were dissected and homogenized in TriZOL reagent (Invitrogen) for RNA extraction and contaminating DNA was removed from the RNA samples using Turbo DNA-free (Ambion). cDNA was synthesized from RNA samples using the SuperScript ${ }^{\oplus}$ III First-Strand Synthesis System (Invitrogen). Relative expression levels for LRIM1, LRRD7, NOS, TEP1, DEF1 and APL1 [68] were analysed with Maxima SYBR green/ROX qPCR Master Mix (Fermentas ThermoScientific) on an ABI 7300 Sequence Detection System (Applied Biosystems). Expression levels were calculated using the $2^{-\Delta \Delta C t}$ method relative to the ribosomal protein s7 gene [9]. Data from biological replicates with separate cohorts of mosquito were used for statistical analysis.

\section{Preparation of $A$. stephensi for LC-MS/MS}

Midguts from a total of 100 3-5 day old female A. stephensi fed with P. falciparum-infected blood and $10 \mu \mathrm{M}$ BIRB796 or an identical infected blood meal supplemented with an equivalent volume of DMSO (diluent) as a control were collected $24 \mathrm{~h}$ post-blood feeding. Midgut samples were then lysed (50 mM Tris pH 6.8, 2 \% SDS, 5 \% Glycerol, $1 \mathrm{mM}$ DTT, 3X protease and phosphatase inhibitor cocktail (Thermo Scientific) on ice for $50 \mathrm{~min}$ and centrifuged at $14,000 \mathrm{~g} / 4{ }^{\circ} \mathrm{C}$ for $15 \mathrm{~min}$. Protein concentrations in the supernatant were determined by BCA protein assay kit (Thermo Scientific) and $60 \mu \mathrm{g}$ of total protein from each sample was electrophoretically separated by SDS-PAGE 
electrophoresis, and cut into 10 pieces. The following processes refer to the method in [63]. Specifically, when Scaffold (version Scaffold 3.5.1, Proteome Software Inc.) was used to validate MS/MS based peptide and protein identifications, peptide identifications were accepted if they could be established at greater than $95.0 \%$ probability as specified by the Peptide Prophet algorithm [69]. Protein identifications were accepted if they could be established at greater than $99.0 \%$ probability and contained at least 2 identified peptides. Protein probabilities were assigned by the Protein Prophet algorithm [70]. Proteins that contained similar peptides and could not be differentiated based on MS/MS analysis alone were grouped to satisfy the principles of parsimony. Using the parameters above, the False Discovery Rate (FDR) was calculated to be $0.3 \%$ on the protein level and $0 \%$ on the peptide level for the A. gambiae search set and $0.3 \%$ on the protein level and $0 \%$ on the peptide level for the $A$. stephensi search set [71]. Differential protein expression between BIRB796 and DMSO treatments were calculated using the Fisher's exact $\mathrm{t}$-test of the Scaffold program based on the total number of assigned spectra per protein.

\section{ROS assays}

For detection of mitochondrial superoxide, groups of 50 (3-5 day old) female A. stephensi were held on water overnight, then allowed to feed for $30 \mathrm{~min}$ on an ATPsaline solution $(150 \mathrm{mM} \mathrm{NaCl}, 10 \mathrm{mM} \mathrm{NaHCO} 3$ and $1 \mathrm{mM}$ ATP) supplemented with equivalent volumes of $10 \mu \mathrm{M}$ BIRB796 or DMSO as a control. Non-fed mosquitoes were removed at the end of $30 \mathrm{~min}$. At $6 \mathrm{~h}$ post feeding, two pools of 10 midguts for each treatment were dissected and incubated in $150 \mu \mathrm{l}$ of $5 \mu \mathrm{M}$ MitoSOX Red (Molecular Probes-Life Technologies) in wells of a 96-well plate. The plate was incubated in the dark at room temperature for $30 \mathrm{~min}$ and then read at excitation $485 \mathrm{~nm}$ and emission $560 \mathrm{~nm}$ (Hidex Chameleon, LabLogic). Non-fed mosquito midguts were used to define baseline superoxide levels. Confocal images were prepared from additional midguts from the same feeding groups. For microscopy, midguts were mounted in Prolong Gold with DAPI (Molecular Probes), imaged using an Olympus FV1000 confocal microscope (Olympus) and processed using ImageJ [72] and Adobe Photoshop. Experiments were replicated four times with separate cohorts of mosquitoes.

For detection of midgut peroxides, 50 (3-5 day old) female A. stephensi were held on water overnight, and then allowed to feed for $30 \mathrm{~min}$ on an ATP-saline solution containing $2 \mathrm{mM}$ paraquat (Sigma-Aldrich) supplemented with equivalent volumes of $10 \mu \mathrm{M}$ BIRB796 or DMSO as a control. Pools of 5 dissected midguts in $50 \mu \mathrm{L}$ PBS (two per treatment) were homogenized by brief sonication and centrifuged to pellet debris. Peroxide levels were estimated in $20 \mu \mathrm{L}$ of sample supernatant in duplicate using the Pierce Quantitative Peroxide assay kit per manufacturer's instructions. Samples were incubated for $20 \mathrm{~min}$ at room temperature prior to spectrophotometer reading. Peroxide assay experiments were replicated three times with separate cohorts of mosquitoes.

\section{Oxidative stress survivorship assays}

100 female 3-5 day old $A$. stephensi were kept on water for $48 \mathrm{~h}$, and then fed for $30 \mathrm{~min}$ on a saline/ATP solution supplemented with $1 \mathrm{mM}$ paraquat (Sigma-Aldrich) and $10 \mu \mathrm{M}$ BIRB796 or an equivalent volume of DMSO as a control. Dead mosquitoes were removed and counted from 8-72 $\mathrm{h}$ after feeding. The experiment was replicated three times with separate cohorts of mosquitoes.

\section{Pyruvate and lactate quantification}

For quantification of pyruvate and lactate, 300 midguts/ treatment were resuspended in $300 \mu \mathrm{l}$ of ice-cold $5 \%$ PCA and homogenized on ice with $4 \times 30$ s strokes with a hand homogenizer. The resulting suspension was centrifuged at $10,300 \mathrm{~g}$ for $5 \mathrm{~min}$ at $4{ }^{\circ} \mathrm{C}$. The supernatants were collected and neutralized with $65 \mu \mathrm{l}$ of $1 \mathrm{M} \mathrm{K}_{2} \mathrm{CO}_{3}$ visualized with $2.5 \mu \mathrm{l}$ of $0.05 \%$ methyl orange [73]. The neutralized extracts were then used for the quantification of pyruvate levels as described elsewhere [73], with minor modifications [74]. The assay was performed at $37^{\circ} \mathrm{C}$ with $50 \mu \mathrm{l}$ of neutralized extract and $200 \mu \mathrm{l}$ of a reaction mixture consisting of $0.2 \mathrm{mM} \mathrm{NADH}$ in $0.2 \mathrm{M} \mathrm{K}_{2} \mathrm{HPO}_{4}$ (pH 8.0). The baseline was recorded at $340 \mathrm{~nm}$ for $3 \mathrm{~min}$ and then again for $10 \mathrm{~min}$ upon addition of $0.5 \mathrm{U} / \mathrm{ml}$ $\mathrm{LDH}$. Levels of pyruvate were calculated using the NADH molar extinction coefficient $\left(\varepsilon_{340}=6,220 \mathrm{M}^{-1} \mathrm{~cm}^{-1}\right)$ and expressed as $\mathrm{pmol} / \mathrm{midgut}$.

Lactate levels were evaluated as described in [74] in the same neutralized supernatant used for pyruvate measurements. Final reaction volume was $200 \mu \mathrm{l}$ and the assay was run at $37{ }^{\circ} \mathrm{C}$. A total of $50 \mu \mathrm{l}$ of midgut extract were added to $100 \mu \mathrm{l}$ of glycine hydrazine buffer (prepared exactly as described in [73] and $1 \mathrm{mM} \mathrm{NAD}^{+}$. The baseline was recorded at $340 \mathrm{~nm}$ for $3 \mathrm{~min}$, followed by addition of $2.5 \mathrm{U} / \mathrm{ml} \mathrm{LDH}$. Changes in absorbance were recorded for $10 \mathrm{~min}$ and lactate levels were calculated using the NADH molar extinction coefficient and expressed as $\mathrm{pmol} / \mathrm{midgut}$. Both pyruvate and lactate measurements were carried out in triplicate using a Tecan Infinite M200 microplate reader. Calibration curves carried out with sodium pyruvate and sodium lactate $(0-2 \mu \mathrm{M})$ showed a detection limit of 0.6 and $0.3 \mu \mathrm{M}$, respectively, with a coefficient of variation $<3 \%$. 
Identification and characterization of $A$. stephensi PGC-1

BLAST analysis of the A. gambiae genome with the human PGC-1 $\alpha$ gene sequence revealed AGAP004361 as the highest similarity sequence, sharing the characterized RNA recognition motif (RRM). A. stephensi ASTEI08687 is the ortholog of AGAP004361 as well as the ortholog of D. melanogaster Spargel/PGC-1 [60]. The homology between A. stephensi ASTEI08687 and Spargel is also greater than that between Spargel and human PGC-1 $\alpha$. Primers for A. stephensi ASTE002911 were designed using Primer Express software (Applied Biosystems): forward 5'-GGTGGTTCAAAGGCAAGTGT-3' and reverse 5'-GCTTGTCTGGCTTGGCTATC-3'.

Midguts from A. stephensi fed with P. falciparum-infected blood supplemented with $10 \mu \mathrm{M}$ BIRB796 or an equivalent volume of DMSO as a control were collected 6 and $24 \mathrm{~h}$ post-blood feeding. Midgut RNA was extracted and cDNA was synthesized as described above. Relative expression levels for AsPGC-1 were analysed with Maxima SYBR green/ROX qPCR Master Mix (Fermentas ThermoScientific) on an ABI 7300 Sequence Detection System (Applied Biosystems). Expression levels were calculated using the $2^{-\Delta \Delta \mathrm{Ct}}$ method relative to the ribosomal protein s7 gene [9]. Data from biological replicates with unique and separate groups of mosquito were used for statistical analysis.

\section{Statistical analyses}

For parasite infection studies, data from three independent experiments with separate cohorts of mosquitoes were analysed for the main effects of experiment and treatment. Infection levels in controls from these replicates were not significantly different from one another (ANOVA), so these data were combined for statistical analysis. Differences in prevalence of infection (the presence of at least one oocyst in a dissected mosquito) between treatment conditions were determined by Fisher's exact test. For survival studies, the data were analyzed in GraphPad using Log-rank (Mantel-Cox) and Gehan-Breslow-Wilcoxon analysis. For all other data sets, significance was determined by Student's t-test (alpha $=0.05$ ) or with oneway ANOVA followed by Bonferroni's post-test for multiple comparisons.

\section{Results}

\section{Identification and characterization of $A$. stephensi p38 MAPK}

The A. gambiae p38 MAPK amino acid sequence [31] was used as a query to identify and annotate the fulllength coding sequence of AsP38 MAPK (ASTEI06041). As in A. gambiae, the AsP38 MAPK genomic sequence spans seven exons and six introns (Fig. 1a), suggesting the existence of an ancestral p38 MAPK that predates the divergence of Anopheles spp. Full-length AsP38

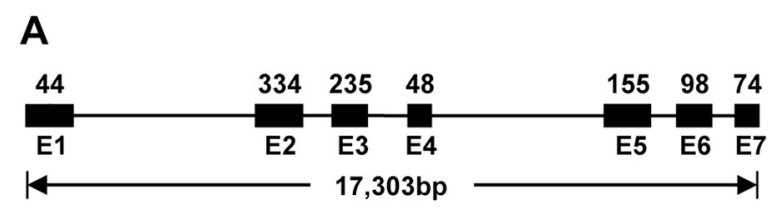

B

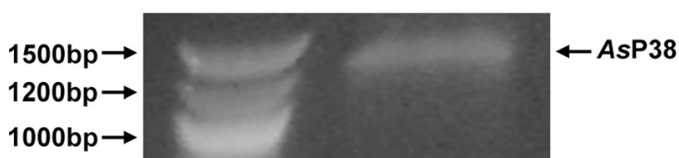

Fig. 1 Gene structure and expression of A. stephensi p38 MAPK. (a) The A. stephensi p38 (AsP38) MAPK gene includes 7 exons (black boxes; length in base pairs (bp) indicated), 6 introns, and spans 17,303 bp. (b) Total RNA was isolated and converted to cDNA from 30 dissected midguts from non-blood fed female A. stephensi. AsP38 MAPK-specific primers were used to amplify cDNA by conventional PCR; molecular standards (bp) are shown on left

MAPK mRNA is expressed in the midgut epithelium of non-blood fed female A. stephensi (Fig. 1b). Across the length of encoded sequence, AsP38 MAPK shares $74 \%$ identity with human and mouse p38 MAPKs (not shown), allowing for the use of tools developed for mammalian p38 MAPKs (e.g., monoclonal antibodies, small molecule inhibitors) in our studies.

To determine whether AsP38 MAPK phosphorylation and, hence, activation occurs in mosquito cells in response to stimulus with pathogen-associated molecular patterns (PAMPs), we used LPS as a prototypical bacterial PAMP and PfPs as a malaria parasite-specific stimulus. LPS can activate p38 MAPK signaling in the mosquito Aedes aegypti [23] and in D. melanogaster [19, 20, 37], so we reasoned that LPS should increase AsP38 MAPK phosphorylation. Accordingly, immortalized $A$. stephensi embryonic (ASE) cells were stimulated with $1 \mu \mathrm{g} / \mathrm{ml}$ LPS and AsP38 MAPK phosphorylation levels were measured over the course of $24 \mathrm{~h}$. LPS stimulation resulted in a significant and rapid increase in phosphorylated AsP38 MAPK that returned to levels not different from control by $30 \mathrm{~min}$ to $1 \mathrm{~h}$ after stimulation (Fig. 2a and 2b), confirming inducible p38 MAPK phosphorylation in A. stephensi that was analogous to that described in other organisms. In addition, ASE cells were stimulated with purified soluble P. falciparum products (PfPs, 36 parasite equivalents/cell) to confirm that parasite products alone could induce the AsP38 MAPK pathway. PfPs was prepared as previously described [66] and tested negative for LPS contamination. We observed a significant increase in phosphorylated $A s$ P38 MAPK levels at 5 min post stimulation in response to PfPs that was reduced below control levels by $30 \mathrm{~min}$ (Additional file 1), confirming that parasite products, in the absence of LPS, can activate this pathway.

To determine whether AsP38 MAPK was activated in vivo in response to malaria parasite infection, female 


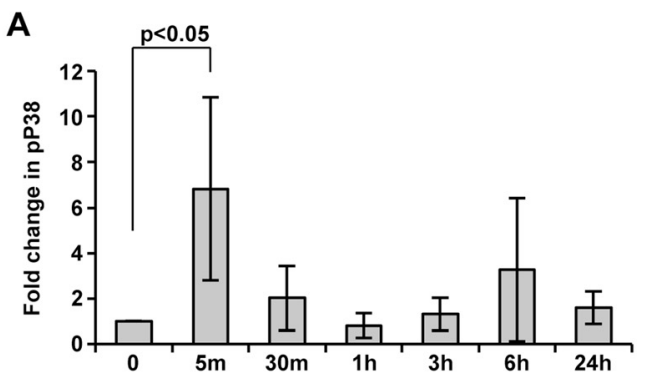

C

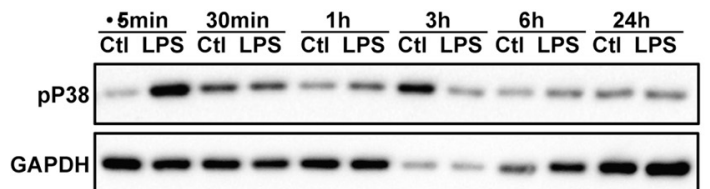

B

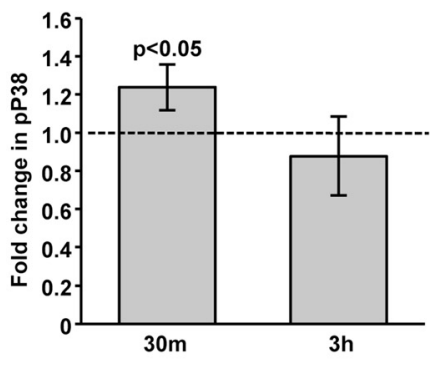

D

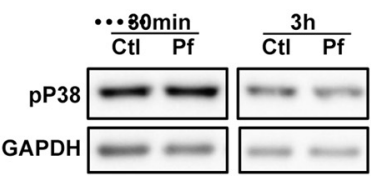

Fig. 2 Phosphorylation of AsP38 MAPK increased in response to LPS in vitro and to P. falciparum infection in vivo. (a, c) Cell lysates from ASE cells treated with $1 \mu \mathrm{g} / \mathrm{ml}$ LPS were collected at the indicated time points post-treatment and levels of phosphorylated p38 MAPK (pP38) were determined by western blotting. Graph in (a) represents average fold change \pm SEMs of pP38 protein levels normalized to untreated controls, $n=3-4$. GAPDH provided an assessment of protein loading. Pairwise comparisons of treatments versus controls at each time point were analysed by Student's t-test, significant p-values are shown. (c) is a representative western blot. (b, d) Midgut cell lysates from 3-5 day old female A. stephensi mosquitoes fed uninfected or $P$. falciparum-infected blood were collected at $30 \mathrm{~min}$ and $3 \mathrm{~h}$ post feeding and levels of pP38 were determined by western blotting. Graph in (b) represents average fold change \pm SEMs of pP38 protein levels normalized to uninfected blood fed controls, $n=3$. Dotted line represents pP38 levels in uninfected blood fed controls. Pairwise comparisons of treatments versus controls at each time point were analysed by Student's t-test, significant p-values relative to control are shown. (d) is a representative western blot

A. stephensi were fed a blood meal containing P. falciparum-infected red blood cells (RBCs) and midgut AsP38 phosphorylation levels were quantified at $30 \mathrm{~min}$ (immediately after the $30 \mathrm{~min}$ feeding) and $3 \mathrm{~h}$ post-blood feeding. The results revealed a significant increase in AsP38 MAPK phosphorylation in mosquitoes fed $P$. falciparum-infected RBCs at $30 \mathrm{~min}$ post-feeding compared to mosquitoes fed RBCs alone that returned to baseline within $3 \mathrm{~h}$ (Figs. 2c and 2d), a pattern that was consistent with PfPs-induced AsP38 phosphorylation in vitro (Additional file 1). Together, these results demonstrated that AsP38 MAPK is activated in the mosquito midgut in response to $P$. falciparum infection.

\section{Inhibition of AsP38 MAPK abolished phosphorylation of MAPK-activated kinase 2 (MK2) in vitro and in vivo}

MAP kinase-activated protein kinase 2 (MK2) is a primary downstream kinase target of p38 MAPK and is commonly used to confirm p38 MAPK activity. Studies in mammals have confirmed that activated MK2 mediates p38 MAPK-dependent stabilization and efficient translation of short-lived mRNAs (reviewed in [75]). Highly homologous MK2 proteins are encoded in the $A$. gambiae (AGAP011890) and A. stephensi (ASTEI05089) genomes, suggesting that a conserved p38 MAPK-MK2 pathway exists in these species. To establish that MK2 is a conserved target of AsP38 MAPK activation, we selected the commonly used p38 MAPK small molecule inhibitors SB203580 [76] and BIRB796 [77]. Unlike SB203580, which directly competes with ATP binding to block kinase activity, BIRB796 induces a conformational change in p38 MAPK making it incompatible with ATPbinding and abolishing its kinase activity [78]. The residues in the active site of p38 MAPK that are necessary for BIRB796 binding are $100 \%$ conserved in A. stephensi [78], as is the ATP binding site that SB203580 interacts with (not shown) [79]. BIRB796 also blocks p38 MAPK phosphorylation and p38 MAPK nuclear localization that occurs in response to DNA damage [80]. We used SB203580 and BIRB796 side-by-side in a number of assays to confirm targeting of AsP38 MAPK (and lack of an effect on $P$. falciparum growth, see below), but carried forward with BIRB796 in our remaining assays because of its minimal off-target effects [78] at the concentrations used in this study.

Treatment with either SB203580 or BIRB796 completely abrogated MK2 phosphorylation in ASE cells in vitro in response to $1 \mu \mathrm{g} / \mathrm{ml}$ LPS (Fig. 3a), establishing the efficacy of these small molecule inhibitors for use in A. stephensi and confirming that MK2 is a phosphorylation target of AsP38 MAPK during PAMP activation. Based on the different modes of action of these inhibitors, these results also confirmed that the observed effects were not influenced by local concentrations of ATP that may have obscured the inhibition pattern of AsP38 MAPK. Provision of SB203580 and BIRB796 in a 


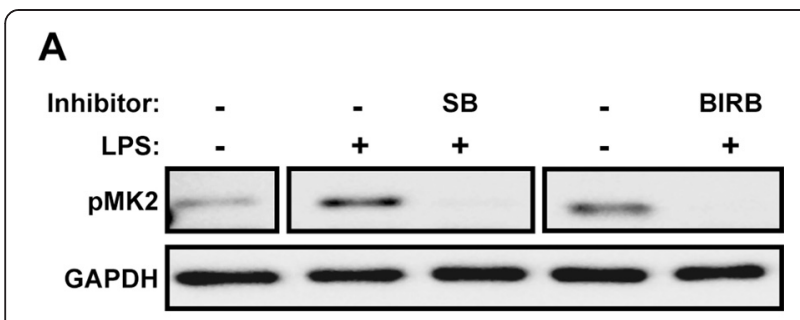

B
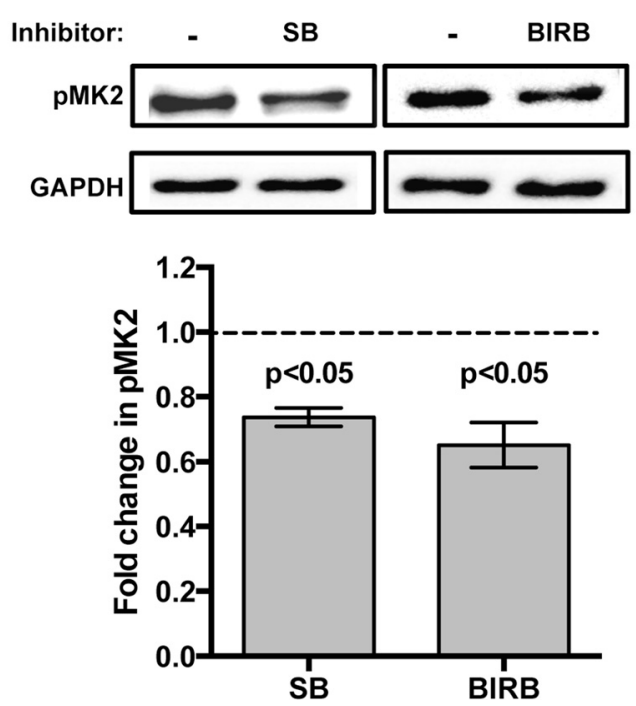

Fig. 3 Inhibition of AsP38 MAPK reduced phosphorylation of MAPKactivated kinase 2 (MK2) in vitro and in vivo. a Representative western blot of phosphorylated MK2 (pMK2) from ASE cells pretreated with $10 \mu \mathrm{M}$ SB203580 (SB), $10 \mu \mathrm{M}$ BIRB796 (BIRB), or an equivalent volume of DMSO as a control for $2 \mathrm{~h}$ and then stimulated with $1 \mu \mathrm{g} / \mathrm{ml}$ LPS for 15 min. GAPDH provided an assessment of protein loading. b Representative western blot of phosphorylated midgut MK2 (pMK2) from A. stephensi fed a P. falciparum-infected blood meal supplemented with $10 \mu \mathrm{M}$ SB203580 (SB), $10 \mu \mathrm{M}$ BIRB796 (BIRB), or an equivalent volume of DMSO; tissues were dissected at $2 \mathrm{~h}$ post-feeding for analysis. Graph represents fold change \pm SEMs of pMK2 protein levels normalized to untreated controls, $n=3$. Pairwise comparisons of treatments versus controls at each time point were analysed by Student's t-test, significant p-values are shown

P. falciparum-infected blood meal reproducibly reduced, but did not completely inhibit, MK2 phosphorylation in the A. stephensi midgut at $2 \mathrm{~h}$ after feeding (Fig. 3b).

\section{Inhibition of AsP38 MAPK decreased P. falciparum development in $A$. stephensi}

Having confirmed that AsP38 MAPK is activated by $P$. falciparum infection, we sought to determine the impact of AsP38 MAPK-dependent signaling on $P$. falciparum development in the mosquito. Female A. stephensi mosquitoes were provided identical infectious blood meals enriched with $P$. falciparum gametocytes that were supplemented with 0.1-10 $\mu \mathrm{M}$ SB203580, $10 \mu \mathrm{M}$ BIRB796, or with an equivalent volume of DMSO as a diluent control and the number of oocysts per midgut were quantified at 10 days post-blood feeding. Two-way ANOVA for each inhibitor indicated no significant differences in control infection levels among replicates, thus data from the replicates were combined for analysis. Treatment with $10 \mu \mathrm{M}$ SB203580 resulted in a $70 \%$ decrease in infection intensity from 14.3 to 4.3 oocysts per midgut (Fig. 4a). Prevalence of infection (the presence of at least one oocyst in a dissected mosquito) decreased significantly from $85 \%$ to $60 \%$ following treatment with $10 \mu \mathrm{M}$ SB203580 (Fig. 4b). Treatment of mosquitoes provided infectious blood meals supplemented with $10 \mu \mathrm{M}$ BIRB796 also yielded significant reductions in infection intensity and prevalence (Fig. 4c and $4 \mathrm{~d}$ ). These data suggested that AsP38 MAPKdependent signaling alters mosquito biology in a manner that benefits malaria parasite development.

Although $P$. falciparum does not encode a prototypical p38 MAPK, the parasite genome does encode two MAPKs: Pfmap-1 which is orthologous to ERK7/8 and Pfmap-2 which is not directly orthologous to any mammalian MAPK subfamilies [81]. In addition, some p38 MAPK inhibitors have been shown to reduce the replication of asexual stage $P$. falciparum [82]. Therefore, we sought to confirm that the observed effects on oocyst development in A. stephensi were due to inhibition of mosquito AsP38 MAPK signaling rather than inhibitor-induced alterations of the intrinsic growth of the parasite. To this end, we quantified DNA content over time as a measure of growth of synchronized asexual $P$. falciparum parasites treated with 1 and $10 \mu \mathrm{M}$ SB203580 and BIRB796 in vitro. We observed no significant effects on parasite growth following treatment with either inhibitor (Fig. 4e). Although this growth assay cannot be performed efficiently on mosquitostage parasites, we infer from these data that the infection patterns observed in vivo using p38 MAPK inhibitors are likely not due to direct negative effects on parasite development in the mosquito. However, given the limitations of our assay, we cannot rule out the possibility that these inhibitors could interfere with ookinete development, parasite migration through the epithelium, or the development of oocysts and sporozoites.

Inhibition of AsP38 MAPK altered antimicrobial peptide promoter activity in response to LPS or peptidoglycan (PGN) stimulation in immortalized $A$. stephensi cells

Because p38 MAPK signaling is critical to innate immune responses [83], we sought to determine the extent to which AsP38 MAPK could regulate NF-кB-dependent promoter activity in mosquito cells in vitro. We utilized a luciferase-reporter assay to quantify the response of mosquito cells in vitro to the bacterial PAMPs LPS and peptidoglycan (PGN). ASE cells were stimulated with either LPS or PGN and promoter activities of the NF- 

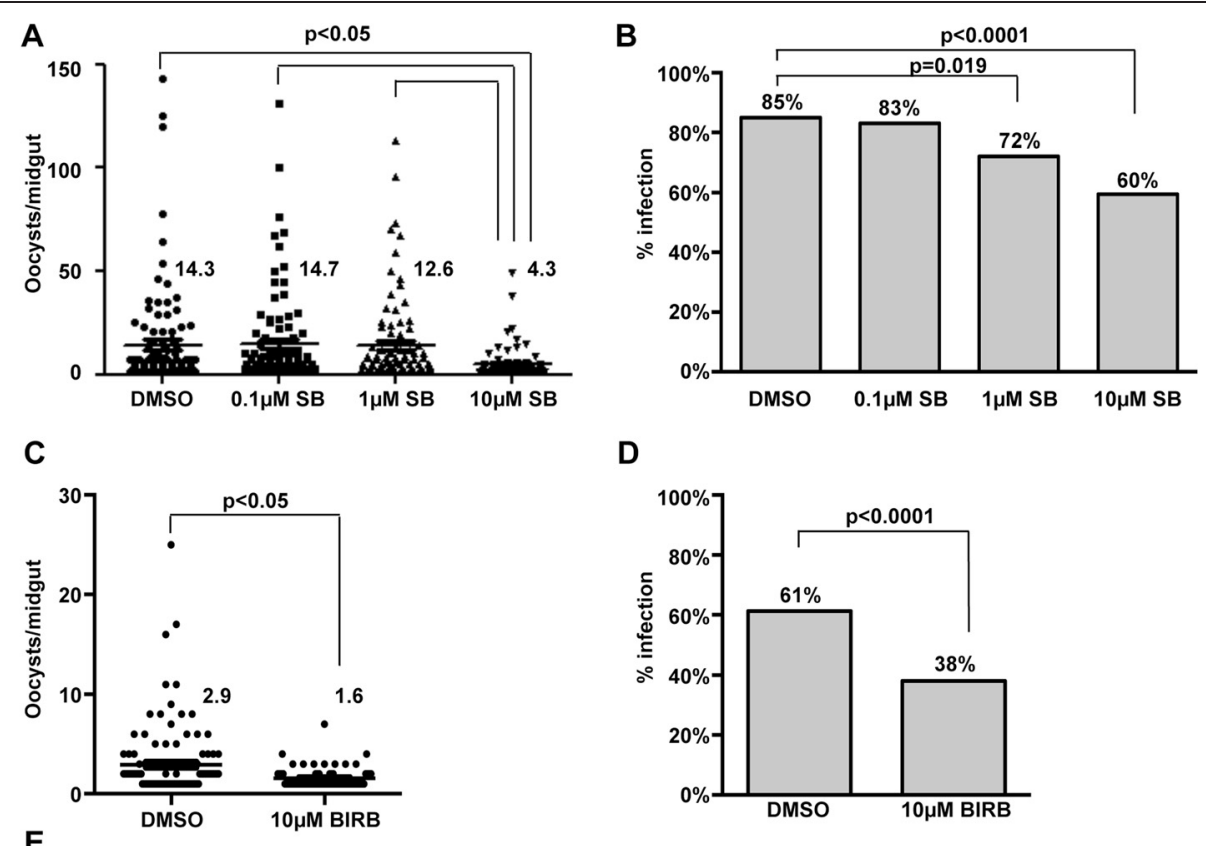

D
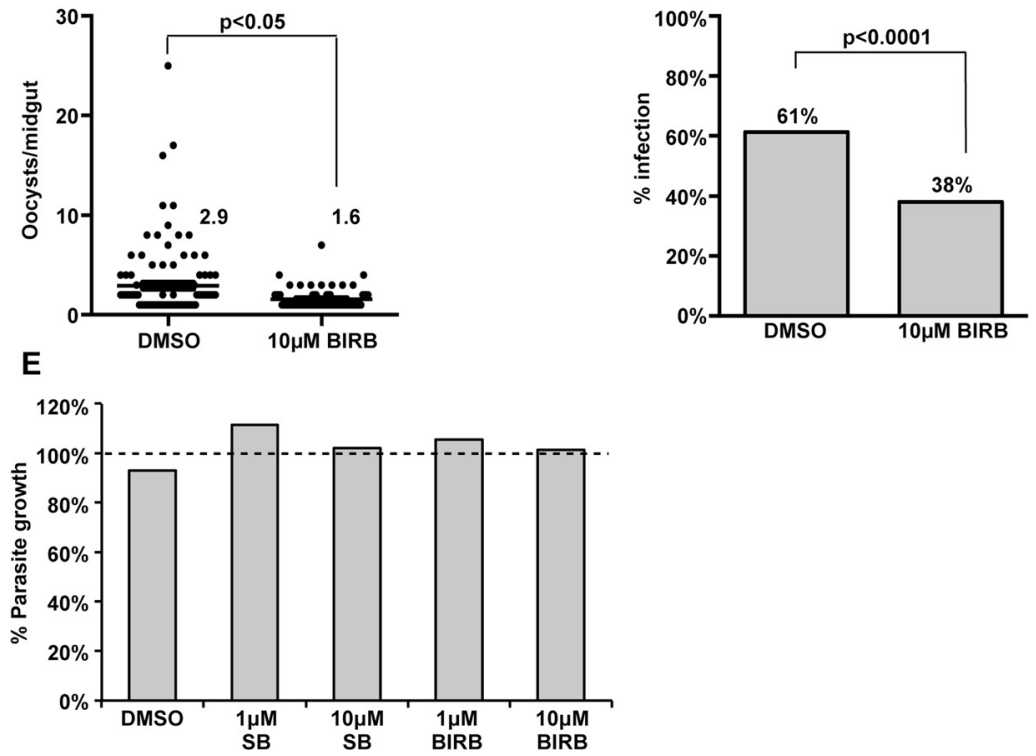

Fig. 4 Inhibition of AsP38 MAPK signaling reduced P. falciparum development in A. stephensi. Mosquitoes were provided with a P. falciparum-infected blood meal supplemented with (a, b) 0.1-10 $\mu \mathrm{M}$ SB203580 (SB) or (c, d) $10 \mu \mathrm{M}$ BIRB796 (BIRB) or an equivalent volume of DMSO as a control. Midguts were dissected and oocysts were counted at 10 days following infection. The experiment was replicated three times with separate cohorts of mosquitoes and analysed by ANOVA to determine if the oocyst intensity in the controls differed amongst replicates. No difference was found, and the data were pooled across replicates and analysed by Kruskal-Wallis to test for overall significance and Dunn's post-test for pairwise comparisons of means. Significant p-values are shown for mean oocysts per infected midgut (zero values excluded). Prevalences of infection (mosquitoes with at least one $P$. falciparum oocyst) are shown as percentages of dissected mosquitoes. Fisher's exact test was used to test for significance. (e) $P$. falciparum cultures were incubated with $1 \mu \mathrm{M}$ or $10 \mu \mathrm{M}$ of SB203580 or BIRB796 or equivalent volume of DMSO as a control for 48 h. Graph represents average relative growth compared to untreated controls (dotted line) at $48 \mathrm{~h}, n=3$. Pairwise comparisons of treatments versus control were analysed by Student's t-test. No significant differences among control and treatment groups were found

кB-dependent antimicrobial peptide (AMP) genes Defensin1, Cecropin1, and Gambicin were measured in the presence of vehicle (DMSO) or following pre-treatment with $0.1-10 \mu \mathrm{M}$ of BIRB796 in DMSO. All three promoter-reporters were induced by LPS and PGN as previously described [7, 66, 68] (Fig. 5). As expected, treatment with BIRB796 alone did not alter activity of the Defensin1, Cecropin1, or Gambicin promoters in ASE cells (Fig. 5). Further, although BIRB796 pre-treatment had no effect on Gambicin promoter activity (Fig. 5, middle panel), pre-treatment with $10 \mu \mathrm{M}$ BIRB796 significantly increased LPS- and PGN-dependent Cecropin1 promoter activity (Fig. 5, top panel) and significantly decreased LPSdependent Defensin1 promoter activity (Fig. 5, bottom panel), suggesting that the pattern of AsP38 MAPK regulation of $A$. stephensi antimicrobial peptide expression in vitro are gene- and stimulus-specific.

Inhibition of AsP38 MAPK increased parasite-inducible expression of immune genes in the $A$. stephensi midgut Our in vitro data indicated that AsP38 MAPK both positively and negatively regulated the expression of antimicrobial peptide genes, suggesting that activation of this pathway facilitates parasite development in vivo via changes in anti-parasite effector genes. To test this hypothesis, we used gene-specific primers to examine midgut transcript expression levels of nitric oxide synthase (NOS; ASTE008593), LRIM1 (ASTE000814), TEP1 

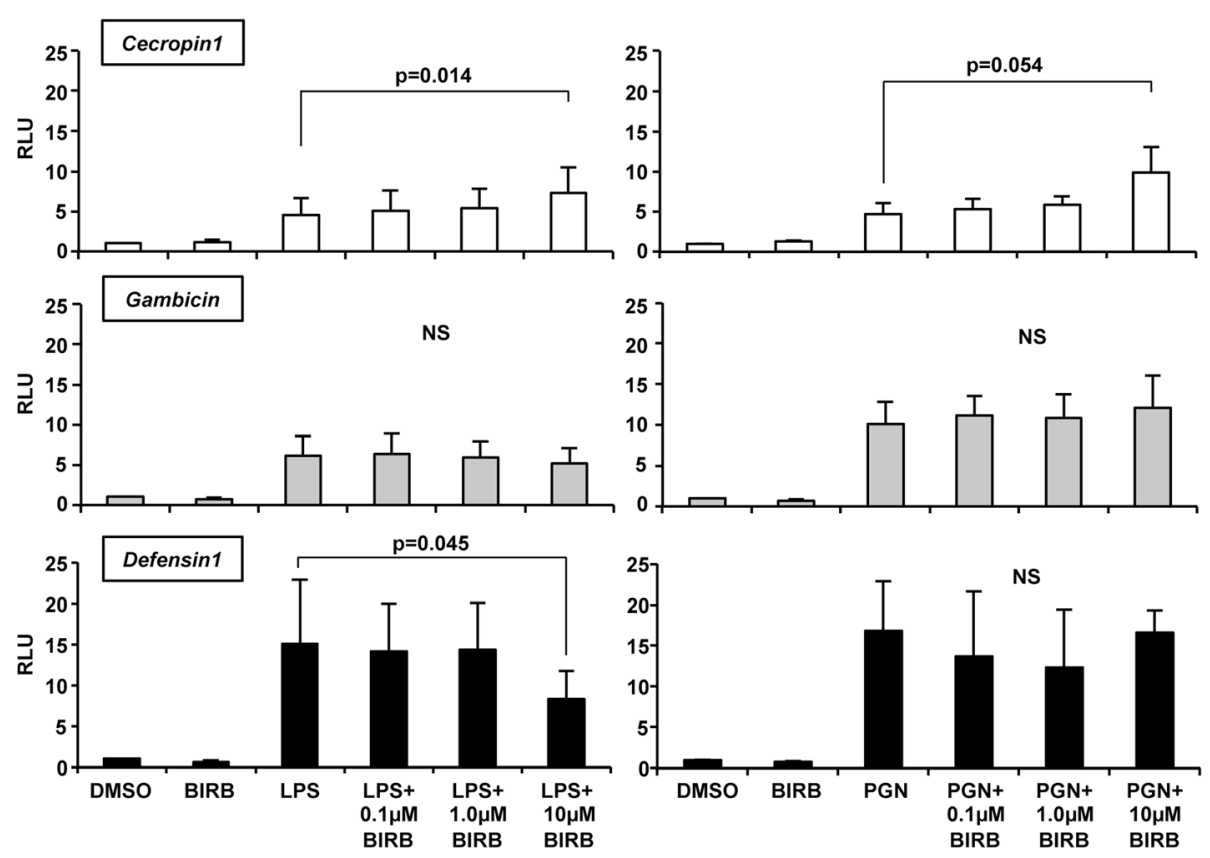

Fig. 5 Inhibition of AsP38 MAPK altered antimicrobial peptide promoter activity in response to LPS or PGN stimulation in immortalized A stephensi cells. ASE cells were transfected with an antimicrobial peptide luciferase promoter-reporter plasmid construct and stimulated $24 \mathrm{~h}$ later with $100 \mu \mathrm{g} / \mathrm{ml}$ LPS or $2 \mu \mathrm{g} / \mathrm{ml} \mathrm{PGN}$ with $0.1-10 \mu \mathrm{M}$ BIRB796 or an equivalent volume of DMSO as a control. Graphs represent means \pm SEMs of luciferase activity (relative light units, RLU) normalized to untreated controls, $n=3-7$. Cecropin 1 (top, white) or Gambicin (middle, gray), or Defensin 1 (bottom, black) promoter activities are indicated. Data were analysed by Student's t-test and significant p-values are shown. NS = not significant

(ASTE010227), APL1 (ASTEI02571), LRRD7/LRIM17 (ASTE009590) and Defensin1 (DEF1; ASTE011281), following blood meals containing $P$. falciparum freeze/thaw parasite products (FTPP) in the presence or absence of $10 \mu \mathrm{M}$ BIRB796 over the course of $24 \mathrm{~h}$. Inhibition of AsP38 MAPK activity induced the expression of almost all anti-malarial effector genes at $6 \mathrm{~h}$ (only NOS and APL1 were marginally not significant), with a return to baseline expression levels by $24 \mathrm{~h}$ after feeding (Fig. 6). In contrast, DEF1 gene expression was decreased after AsP38 MAPK inhibition, consistent with in vitro promoter activity following LPS stimulation (Fig. 5). These data suggested that AsP38 MAPK-dependent signaling negatively regulates the activation of immune genes associated with parasite killing, providing a potential mechanistic explanation for the decrease in parasite development observed following inhibition of MAPK activity (Fig. 4).

\section{Inhibition of AsP38 MAPK decreased mosquito antioxidant defenses}

In addition to its role in the regulation of innate immunity, p38 MAPK signaling can also affect stress responses (reviewed in [84]). To understand these and the other potential roles of AsP38 MAPK signaling on a more global level, differential quantitative liquid chromatography/ tandem mass spectrometry (LC-MS/MS) was performed to identify proteins that were over- or underrepresented in A. stephensi fed P. falciparum-infected blood supplemented with $10 \mu \mathrm{M}$ BIRB796 relative to age-matched, female $A$. stephensi fed an identical infected blood meal supplemented with an equivalent volume of DMSO as a control. At $24 \mathrm{~h}$ post-feeding, 13 proteins out of a total of 1,418 proteins were over-represented and 60 were underrepresented following inhibition of AsP38 MAPK (Table 1). These results suggested that AsP38 MAPK promotes protein translation and synthesis as indicated in the literature [45-48].

Among the underrepresented proteins, catalase and SOD2 were significantly reduced by AsP38 MAPK inhibition (Table 1). SOD2 is a mitochondrial manganese SOD that dismutates superoxide anion into hydrogen peroxide and diatomic oxygen; therefore, a reduction in SOD2 levels should result in increased midgut steady-state concentrations of mitochondrial superoxide. To test this hypothesis, we estimated superoxide concentrations in midgut mitochondria of female A. stephensi fed a saline solution containing either $10 \mu \mathrm{M}$ BIRB796 or a saline solution with an equivalent volume of DMSO as a control. At $6 \mathrm{~h}$ post-feeding, mitochondrial superoxide levels in BIRB796-fed mosquitoes were significantly higher than controls (Fig. 7a and 7b). Unmitigated oxidative stress has also been associated with decreased short-term survivorship in p38 MAPK mutants of D. melanogaster [38]. Accordingly, we tested whether reduced antioxidant defenses 


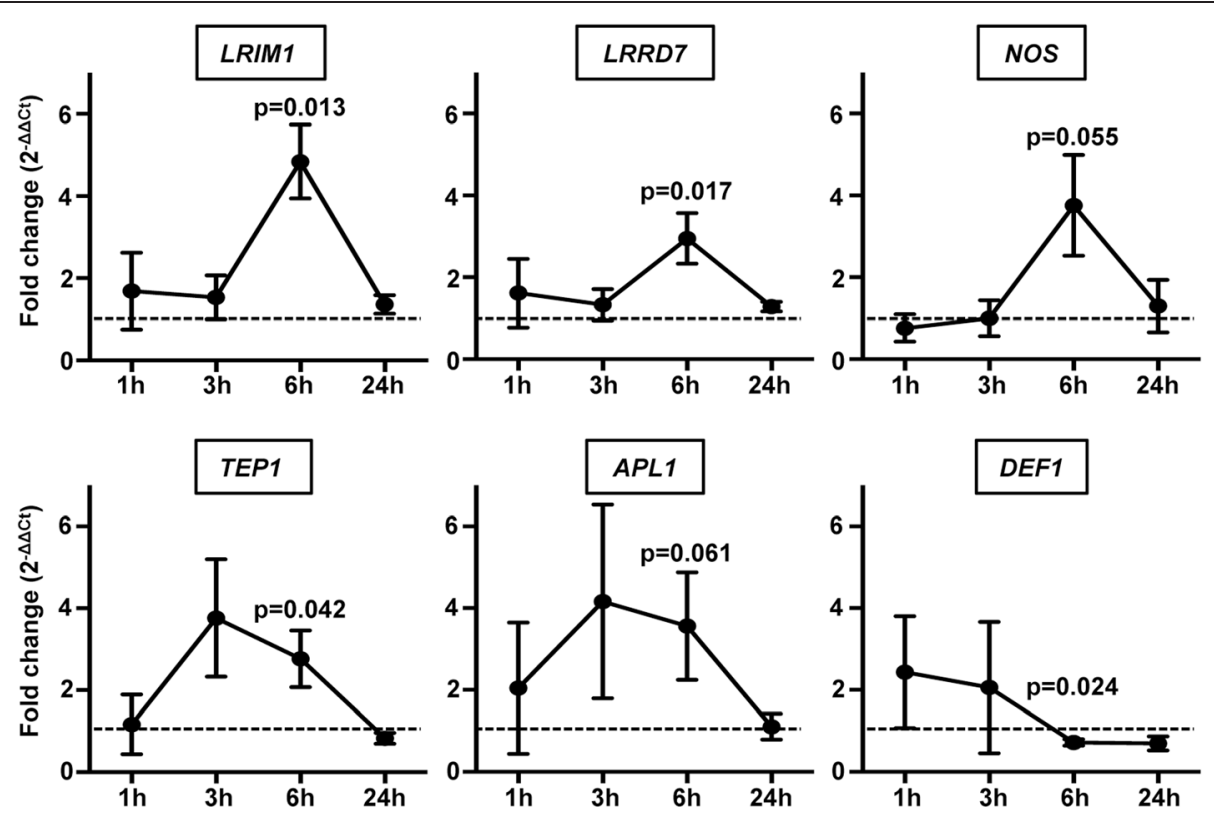

Fig. 6 Inhibition of AsP38 MAPK increased parasite-inducible expression of immune genes in the A. stephensi midgut. Graphs represent means \pm SEMs of fold change in the expression of selected immune genes in the midgut of mosquitoes fed a blood meal with $P$. falciparum freeze/thaw parasite products (FTPP) supplemented with $10 \mu \mathrm{M}$ BIRB796 or an identical FTPP meal supplemented with an equivalent volume of DMSO as a control. Pairwise comparisons of treatments and matched controls were analysed by Student's t-test; significant and marginally significant $p$-values are shown, $n=3-5$

(SOD2, catalase) could be associated with reduced mosquito survivorship in the context of oxidative stress via feeding of a saline meal with $2 \mathrm{mM}$ paraquat (an inducer of superoxide anion production via redox cycling [85]) in DMSO or with $2 \mathrm{mM}$ paraquat and $10 \mu \mathrm{M}$ BIRB. As expected, midgut peroxide levels relative to controls were increased, albeit marginally significantly, by inhibition of AsP38 MAPK (Fig. 7c). Inhibition of AsP38 MAPK also resulted in significantly reduced survivorship to acute paraquat challenge compared to the controls (Fig. 7d, Table 2). Taken together, these results indicated that AsP38 MAPK signaling likely enhances mosquito resistance to oxidative stress and that inhibition of this MAPK pathway significantly decreases ROS catabolism.

\section{Increased mitochondrial ROS induced expression of}

\section{A. stephensi immune genes}

In addition to the known ability of high levels of ROS to directly kill malaria parasites [86, 87], moderate levels of ROS can signal in the midgut to activate the mosquito immune response [35, 41, 88]. Therefore, we reasoned that the increase in anti-malarial effector gene expression observed following inhibition of AsP38 MAPK (Fig. 6) could be due, in part, to increased mitochondrial ROS (Fig. 7a and b). To assess the contribution of mitochondrial ROS to the activation of A. stephensi immune genes, mosquitoes were fed a blood meal containing $1 \mu \mathrm{M}$ rotenone, a concentration that can induce mitochondrial superoxide in the $A$. stephensi midgut to approximately 2.5-fold that of control levels [89], consistent with BIRB-induced superoxide levels (Fig. 7b). At $3 \mathrm{~h}$ post-feeding, midguts were collected for analysis of anti-malarial immune gene expression by qRT-PCR. Rotenone treatment alone significantly increased the expression of APL1 and LRRD7 with trends toward increased TEP1 and LRIM1 expression relative to controls (Fig. 8). However, no increased expression was detected for NOS or DEF1 with rotenone treatment (Fig. 8), suggesting that mitochondrial ROS contributes to, but does not fully recapitulate, BIRB796-induced immune gene expression in the A. stephensi midgut.

\section{Inhibition of AsP38 MAPK decreased AsPGC-1 gene expression and mitochondrial protein synthesis in A. stephensi}

Inhibition of AsP38 MAPK was associated with significantly reduced levels of midgut mitochondrial proteins, including NADH-ubiquinone oxidoreductase (Complex I), succinate dehydrogenase (Complex II), cytochrome $c$ oxidase subunit VIIa (Complex IV), ATPase subunit beta (Complex V), 3-hydroxybutyrate dehydrogenase (ketone body metabolism), 3-ketoacyl-acyl carrier protein reductase (fatty acid biosynthesis/quinone reductase), putative mitochondrial inner membrane protein as well as mitochondrial porin and kinesin heavy chain orthologs (Table 1). This broad representation of structural, intermediary metabolism, and OXPHOS proteins suggested that inhibition of AsP38 MAPK significantly 
Table 1 Proteins over- and under-represented in the A. stephensi midgut following inhibition of AsP38 MAPK signaling

\begin{tabular}{|c|c|c|c|c|}
\hline \multicolumn{5}{|c|}{ Over-represented proteins following inhibition of AsP38 MAPK } \\
\hline Pathway or process & Accession number & Protein name & UniProt gene name & $P$ value \\
\hline \multirow[t]{2}{*}{ Carbohydrate metabolism } & ASTEI05125 & maltase 2 (mal2) & MGAM & 0.011 \\
\hline & ASTEI02309 & maltase & MGAM & 0.007 \\
\hline \multirow[t]{6}{*}{ Cytoskeleton/development } & ASTEI01099 & thymosin & TMSNB & 0.041 \\
\hline & ASTEI03296 & dynamin & DNM & 0.023 \\
\hline & ASTEI04270 & gelsolin & GSN & 0.036 \\
\hline & ASTEI05229 & collagen alpha-1 chain & COLA1 & 0.008 \\
\hline & ASTEI08311 & myosin & MYH & 0.001 \\
\hline & ASTEI11230 & coracle & CORA & 0.001 \\
\hline Lysosomes & ASTEI08520 & v-type proton ATPase subunit c & VATC & 0.023 \\
\hline \multirow[t]{2}{*}{ Mitochondria } & ASTEI1 1442 & NADH dehydrogenase 1 beta subcomplex subunit 10 & NDUFB10 & 0.020 \\
\hline & ASTEI08224 & $60 \mathrm{kDa}$ heat shock mitochondrial & HSP60 & 0.006 \\
\hline \multirow[t]{2}{*}{ Membrane fusion/exocytosis } & ASTEI07544 & synaptosomal-associated protein 25 & SNAP25 & 0.003 \\
\hline & ASTEI07916 & Nipsnap & NIPSNAP1 & 0.008 \\
\hline \multicolumn{5}{|c|}{ Under-represented proteins following inhibition of AsP38 MAPK } \\
\hline Pathway or process & Accession number & Protein name & UniProt gene name & $P$ value \\
\hline \multirow[t]{3}{*}{ Glycolysis } & ASTEI06800 & hexokinase type 2 & $\mathrm{HK} 2$ & 0.023 \\
\hline & ASTEI05709 & triosephosphate isomerase & TPI1 & 0.019 \\
\hline & ASTEI07469 & pyruvate kinase & PKM & 0.009 \\
\hline Pentose phosphate shunt & ASTEI07641 & 6-phosphogluconate dehydrogenase & PGD & 0.027 \\
\hline Fatty acid biosynthesis/quinone reductase & ASTEI07966 & 3-ketoacyl-acyl carrier protein reductase & FABG & 0.009 \\
\hline Mitochondrial ketone body metabolism & ASTEI05771 & succinyl-ligase subunit & SUCLA2 & 0.034 \\
\hline \multirow[t]{5}{*}{ Mitochondrial OXPHOS } & ASTEI01282 & succinate dehydrogenase iron-sulfur & SDHB & 0.052 \\
\hline & ASTEI05686 & NADH-ubiquinone oxidoreductase/75 kD & NDUFS1 & 0.029 \\
\hline & ASTEl10851 & cytochrome c oxidase subunit vlla & COX7A1 & 0.034 \\
\hline & ASTEI09954 & ATPase subunit $F$ & ATP5F & 0.004 \\
\hline & ASTEI02184 & 3-hydroxybutyrate dehydrogenase & HIBADH & 0.047 \\
\hline Mitochondrial Krebs cycle & ASTEI01282 & succinate dehydrogenase iron-sulfur & SDHB & 0.052 \\
\hline \multirow[t]{2}{*}{ Mitochondrial protein import/processing } & ASTEI04325 & putative inner membrane protein & IMMT & 0.012 \\
\hline & ASTEI06526 & porin & VDAC & 0.005 \\
\hline Mitochondrial dynamics & ASTEI08858 & kinesin heavy chain & KIF5B & 0.009 \\
\hline Mitochondrial antioxidant defenses & ASTEI07113 & superoxide dismutase 2 & SOD2 & 0.006 \\
\hline \multirow[t]{12}{*}{ Ribosomes/translation } & ASTEI06447 & 40 s ribosomal protein s16 & RPS16 & 0.053 \\
\hline & ASTEI09012 & 40s ribosomal protein s19a & RPS19A & 0.015 \\
\hline & ASTEI08714 & 40s ribosomal protein s3 & RPS3 & 0.017 \\
\hline & ASTEI09336 & 40s ribosomal protein s3a & RPS3A & 0.021 \\
\hline & ASTEI09193 & 40s ribosomal protein sa & RPSA & 0.006 \\
\hline & ASTEI01139 & 60 s ribosomal protein L10 & RPL10 & 0.026 \\
\hline & ASTEI04204 & 60s ribosomal protein L10a & RPL10A & 0.015 \\
\hline & ASTEI00128 & 60 s ribosomal protein L13 & RPL13 & 0.028 \\
\hline & ASTEI09035 & 60s ribosomal protein L15 & RPL15 & 0.001 \\
\hline & ASTEI01482 & 60s ribosomal protein L18 & RPL18 & 0.053 \\
\hline & ASTEI07898 & 60 s ribosomal protein L23 & RPL23 & 0.022 \\
\hline & ASTEI08588 & 60s ribosomal protein L27a & RPL27A & 0.002 \\
\hline
\end{tabular}


Table 1 Proteins over- and under-represented in the A. stephensi midgut following inhibition of AsP38 MAPK signaling (Continued)

\begin{tabular}{|c|c|c|c|c|}
\hline & ASTEI05093 & 60 s ribosomal protein $L 31$ & RPL31 & 0.020 \\
\hline & ASTEI00059 & 60s ribosomal protein $L 36$ & RPL36 & 0.038 \\
\hline & ASTEI00185 & 60 s ribosomal protein $L 4$ & RPL4 & 0.007 \\
\hline & ASTEI10247 & 60 s ribosomal protein $L 5$ & RPL5 & 0.001 \\
\hline & ASTEI01907 & 60 s ribosomal protein $L 7$ & RPL7 & 0.010 \\
\hline & ASTEI063681 & heterogeneous nuclear ribonucleoprotein 40 & HNRNPH1 & 0.034 \\
\hline & ASTEI05590 & polyadenylate-binding protein & PABP & 0.048 \\
\hline & ASTEI08624 & nascent polypeptide-associated complex subunit alpha & NACA & 0.027 \\
\hline & ASTEI1 1090 & signal recognition particle receptor, alpha homolog & SRPR & 0.033 \\
\hline & ASTEI02606 & eukaryotic translation initiation factor 3 subunit e & EIF3E & 0.038 \\
\hline & ASTEI02686 & eukaryotic translation initiation factor 3 subunit i & EIF3| & 0.039 \\
\hline & ASTEI012841 & RNA-binding protein 1 & RBP1 & 0.005 \\
\hline & ASTEI06323 & ribosomal protein 114 & RPL14 & 0.000 \\
\hline & ASTEI06775 & rRNA 2-o-methyltransferase fibrillarin & FBL & 0.022 \\
\hline & ASTEI01829 & cchc-type zinc finger protein & ZCRB1 & 0.034 \\
\hline & ASTEl10281 & nipped-b protein & NIPBL & 0.017 \\
\hline \multirow[t]{4}{*}{ Antioxidant/detoxification } & ASTEI10644 & catalase & CAT & 0.022 \\
\hline & ASTEI07113 & superoxide dismutase 2 & SOD2 & 0.006 \\
\hline & ASTEI03473 & $\begin{array}{l}\text { aldehyde dehydrogenase family } 7 \text { member a1 } \\
\text { homolog }\end{array}$ & ALDH7A1 & 0.003 \\
\hline & ASTEI06895 & cytochrome $b_{5}$ & CYB5 & 0.040 \\
\hline \multirow[t]{8}{*}{ Proteolysis/lysosomes } & ASTEI07459 & membrane alanyl aminopeptidase & ANPEP & 0.001 \\
\hline & ASTEI09440 & hypodermin c & & 0.045 \\
\hline & ASTEI10033 & chymotrypsin-2 & CTRB1 & 0.008 \\
\hline & ASTEI07899 & proteasome subunit alpha type-1 & PSMA1 & 0.039 \\
\hline & ASTEI00715 & endochitinase & CHIT1 & 0.045 \\
\hline & ASTEl10979 & v-atpase subunit $h$ & ATP6V1H & 0.047 \\
\hline & ASTEI07458 & aminopeptidase $n$ & ANPEP & 0.027 \\
\hline & ASTEI03577 & acylsphingosine deacylase & ASAH1 & 0.012 \\
\hline \multirow[t]{4}{*}{ Endocytosis } & ASTEI09008 & Ras-related protein Rab-18-b & RAB18 & 0.017 \\
\hline & ASTEl10979 & v-atpase subunit $h$ & ATP6V1H & 0.047 \\
\hline & ASTEI03296 & dynamin & DNM & 0.023 \\
\hline & ASTEI01514 & ocia domain-containing protein 1 & OCIAD1 & 0.039 \\
\hline Iron storage & ASTEI00707 & ferritin heavy chain & FTH1 & 0.031 \\
\hline \multirow[t]{3}{*}{ Signal transduction } & ASTEI02790 & guanine nucleotide-binding protein subunit beta-1 & GNB1 & 0.003 \\
\hline & ASTEI00708 & protein ubash3a homolog & UBASH3A & 0.016 \\
\hline & ASTEI05550 & phosphatidylethanolamine-binding protein & PEBP1 & 0.005 \\
\hline
\end{tabular}

impacted midgut mitochondrial mass, possibly through inhibition of biogenesis. Further, given that p38 MAPK regulation of PGC-1 orthologs from invertebrates to mammals controls mitochondrial biogenesis, we hypothesized that a reduction in A. stephensi PGC-1 (AsPGC-1) following inhibition of AsP38 MAPK could account for these reductions in mitochondrial proteins. To test this, we examined expression of AsPGC-1 in mosquitoes fed $P$. falciparum-infected RBCs supplemented with $10 \mu \mathrm{M}$ BIRB796 relative A. stephensi fed an identical infected blood meal supplemented with an equivalent volume of DMSO as a control. Inhibition of AsP38 MAPK resulted in a significant decrease in AsPGC-1 gene expression relative to controls (Fig. 9), suggesting that BIRB796 reductions in midgut mitochondrial proteins in A. stephensi are associated with inhibition of PGC-1 expression that is analogous to that observed in other species. 


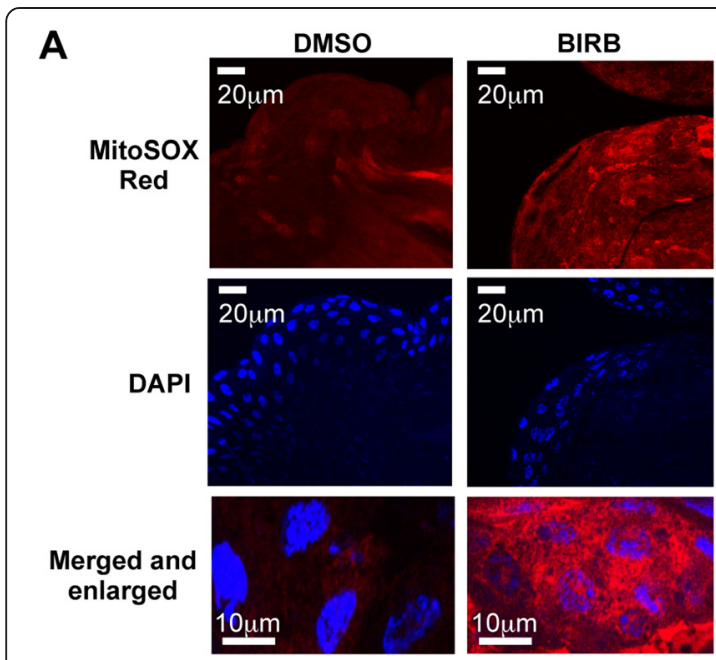

B

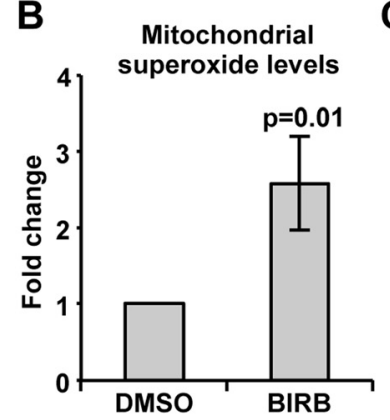

C

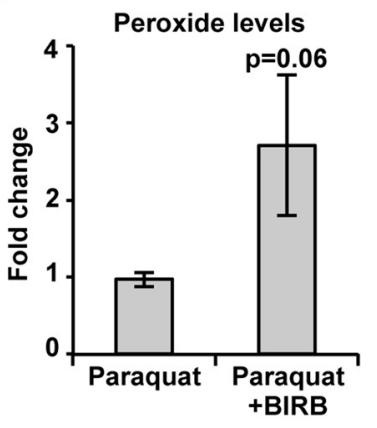

D

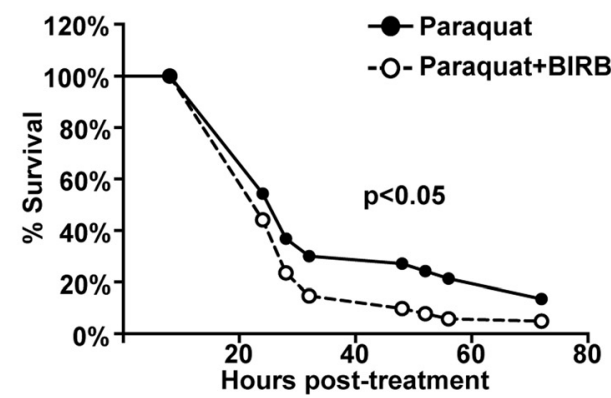

Fig. 7 Inhibition of AsP38 MAPK in A. stephensi increased midgut ROS levels and reduced mosquito survival. A. stephensi females were fed a saline solution containing either $10 \mu \mathrm{M}$ BIRB796 or an equivalent volume of DMSO as a control and 10 midguts/group were collected $6 \mathrm{~h}$ post-feeding. a Representative images from confocal microscopy of MitoSOX Red stained midguts. Upper Panel: MitoSOX Red staining, scale bars $=20 \mu \mathrm{m}$; Middle Panel: DAPI staining scale bars $=20 \mu \mathrm{m}$; Lower Panel: Merged images, scale bars $=10 \mu \mathrm{m}$. $\mathbf{b}$ Graph of A. stephensi midgut mitochondrial superoxide levels as determined by Mitosox Red fluorescence staining. Data were analysed by Student's t-test and are represented as means \pm SEM, $p$-value is shown, $n=4$. c Graph of midgut peroxide levels in A. stephensi fed with saline solution containing $2 \mathrm{mM}$ paraquat with $10 \mu \mathrm{M}$ BIRB796 or an equivalent volume of DMSO as a control at $6 \mathrm{~h}$ post-feeding. Data were analysed by Student's t-test and represented as means \pm SEM, $\mathrm{p}$-value is shown, $n=3$. $\mathbf{d}$ Representative survivorship curve from Table 2 of $A$. stephensi fed a saline solution with $1 \mathrm{mM}$ paraquat supplemented with $10 \mu \mathrm{M}$ BIRB796 or with an equivalent volume of DMSO as a control
Table 2 Inhibition of AsP38 MAPK under conditions of oxidative stress reduces survival of adult female $A$. stephensi

\begin{tabular}{|c|c|c|c|c|}
\hline \multirow[b]{2}{*}{ Exp } & \multicolumn{2}{|c|}{$\begin{array}{l}\text { Median survival } \\
\text { time (hours) }\end{array}$} & \multirow{2}{*}{$\begin{array}{l}\text { Log-rank } \\
\text { (Mantel-Cox) } \\
\text { p-values }\end{array}$} & \multirow{2}{*}{$\begin{array}{l}\text { Gehan-Breslow } \\
\text { Wilcoxon } \\
\text { p-values }\end{array}$} \\
\hline & $\begin{array}{l}\text { Paraquat + } \\
\text { DMSO }\end{array}$ & $\begin{array}{l}\text { Paraquat + } \\
\text { BIRB }\end{array}$ & & \\
\hline 1 & 28 & 24 & 0.004 & 0.026 \\
\hline 2 & 28 & 24 & 0.015 & 0.007 \\
\hline 3 & 32 & 24 & 0.025 & 0.052 \\
\hline
\end{tabular}

AsP38 MAPK signaling regulates glycolysis and protein translation in A. stephensi

Significantly decreased Complex I, II, IV and V subunits suggested that AsP38 MAPK inhibition would be associated with reduced OXPHOS. In addition to mitochondrial biogenesis, p38 MAPK signaling and activation of PGC- $1 \alpha$ and PGC- $1 \beta$ have also been implicated in the control of glucose and lipid homeostasis $[54,55,57,56]$. In particular, PGC- $1 \alpha$ is known to drive expression of the gluconeogenic enzymes PEPCK and G6Pase in liver, while PGC-1 $\beta$ enhances fatty acid oxidation and glycolysis, principally through the activation of glucokinase and PK. At $24 \mathrm{~h}$ following provision of a $P$. falciparum-infected blood meal with $10 \mu \mathrm{M}$ BIRB796, we noted that three proteins associated with glycolysis were under-represented following inhibition of AsP38 MAPK (Table 1), suggesting that these enzymes are positively regulated by AsP38 MAPK signaling. Specifically, we observed decreased levels of hexokinase, triosephosphate isomerase, and PK (Table 1). While these changes indicate an impact on glycolysis, decreased levels of nine key mitochondrial proteins (Table 1) suggest that the main effects of AsP38 MAPK are due to modulation of mitochondrial biogenesis/function (Table 1). In support of

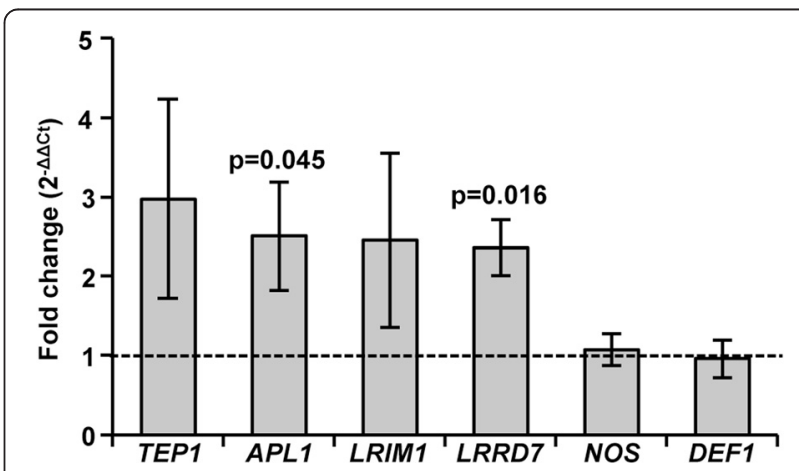

Fig. 8 Mitochondrial ROS induced expression of $A$. stephensi immune genes. Graph represents means \pm SEMs of fold change in the expression of selected immune genes in RNA samples prepared from 30 pooled midguts of mosquitoes fed a blood meal containing $1 \mu \mathrm{M}$ rotenone relative to mosquitoes fed an unsupplemented blood meal (dotted line) at $6 \mathrm{~h}$ post-feeding. Data were analysed by Student's t-test, significant $p$-values are shown, $n=3$ 


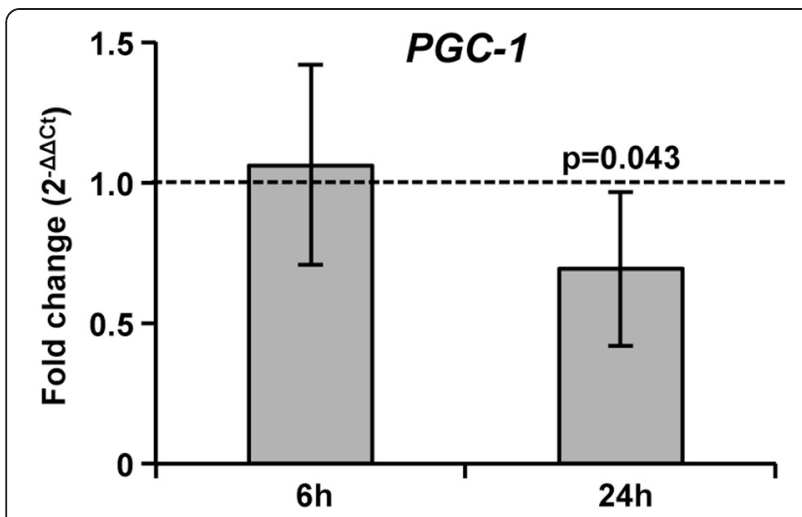

Fig. 9 Inhibition of AsP38 MAPK decreased AsPGC-1 gene expression in the A. stephensi midgut. Mosquitoes were fed with P. falciparuminfected RBCs supplemented with $10 \mu \mathrm{M}$ BIRB796 (BIRB) or an equivalent volume of DMSO as a control (dotted line). Graph represents means \pm SEMs of fold change in the expression of AsPGC-1 in RNA prepared from 30 pooled mosquito midguts, $n=5$. Data were analysed by Student's t-test; significant $p$-values are shown

this hypothesis, reduced glucose consumption and a shift from OXPHOS to glycolysis were observed in midguts from A. stephensi fed a $P$. falciparum-infected blood meal supplemented with $10 \mu \mathrm{M}$ BIRB796 compared to an identical infected blood meal supplemented with an equivalent volume of DMSO as a control. Midgut pyruvate concentrations were decreased at 48 and $72 \mathrm{~h}$ by supplementation with BIRB796 (Fig. 10, top panel), whereas lactate concentrations were significantly increased at $72 \mathrm{~h}$ (Fig. 10, middle panel). By adding pyruvate to lactate at each time point (as an equivalent for total glucose utilization), it is clear that at $48 \mathrm{~h}$ there is a 1.7 -fold increase in glucose consumption upon ingestion of infected blood whereas with BIRB796, no such increase occurs. A higher lactate-to-pyruvate ratio (3.8-fold of controls; Fig. 10, bottom panel) in mosquitoes fed an infectious blood meal containing BIRB796, confirms that AsP38 MAPK is indeed involved in the regulation of midgut glucose catabolism.

Following AsP38 MAPK inhibition, we also noted a significant under-representation of proteins involved in the processes of protein translation and synthesis such as eukaryotic initiation factor (eIF)-3E and -3I, as well a number of ribosomal and RNA-binding proteins (Table 1). Activation of p38 MAPK has been associated with increased protein translation via signaling through MK2, which enhances mRNA stability and translation [47, 90]. Therefore, the loss of midgut MK2 phosphorylation following inhibition of AsP38 MAPK (Fig. 3) likely accounts for the observed decrease in protein translation machinery (Table 1).

Collectively, our inferences regarding proteins in Table 1 were supported by hypergeometric algorithm analysis followed by Benjamini-Hochberg correction for overrepresentation of pathways (Table 3). This analysis indicated
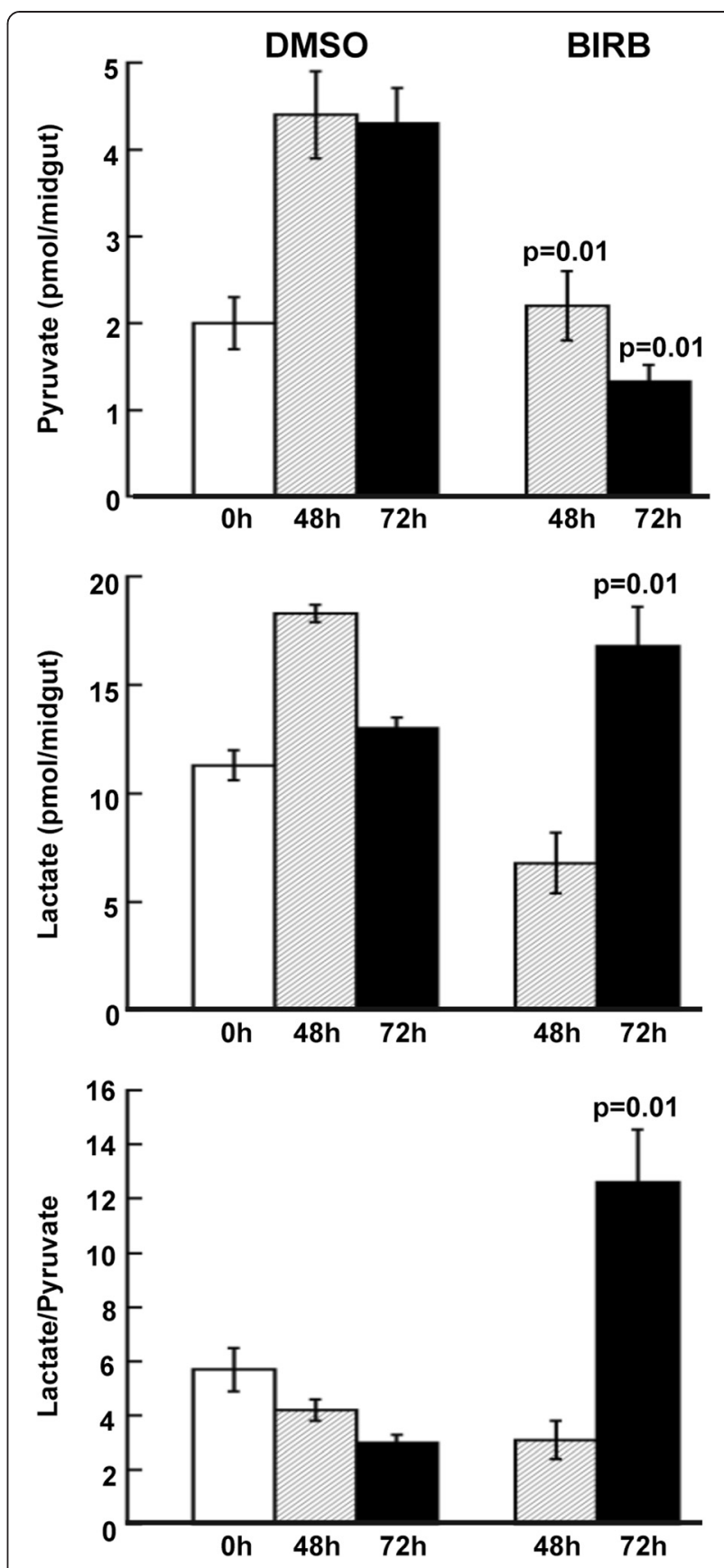

Fig. 10 Inhibition of AsP38 MAPK altered pyruvate and lactate concentrations in the A. stephensi midgut. A. stephensi were fed a $P$. falciparum-infected blood meal supplemented with either $10 \mu \mathrm{M}$ BIRB796 or an equivalent volume of DMSO and 300 midguts/group were collected at 0,48 , and $72 \mathrm{~h}$ post-feeding to determine pyruvate and lactate levels. Graphs represent means \pm SEMs of 3 independent measurements. Statistical analysis was performed by one-way ANOVA, followed by Bonferroni's post-test for multiple comparisons between treatments (BIRB796) and controls (DMSO); significant p-values are shown

that the most affected pathways were those associated with protein translation (ribosome, RNA transport and degradation), glucose catabolism (OXPHOS, TCA cycle, 
Table 3 Over-represented pathways in the A. stephensi midgut upon BIRB796-mediated inhibition of AsP38 MAPK

\begin{tabular}{|c|c|c|c|c|c|c|}
\hline Pathway name ${ }^{a}$ & Pathway ID & $\begin{array}{l}\text { Pathway uploaded } \\
\text { gene count }\end{array}$ & $\begin{array}{l}\text { Genes in InnateDB } \\
\text { for this entity }\end{array}$ & Pathway p-value & $\begin{array}{l}\text { Pathway p-value } \\
\text { (corrected) }\end{array}$ & Gene symbols \\
\hline Ribosome & 474 & 17 & 87 & $2.89 \mathrm{E}-23$ & $1.53 E-22$ & $\begin{array}{l}\text { RPL10; RPL10A; RPL13; RPL14; } \\
\text { RPL15; RPL18; RPL23; RPL27A; } \\
\text { RPL31; RPL4; RPL5; RPL7; RPS16; } \\
\text { RPS19; RPS3; RPS3A; RPSA }\end{array}$ \\
\hline $\begin{array}{l}\text { Oxidative } \\
\text { phosphorylation }\end{array}$ & 576 & 4 & 131 & $6.09 \mathrm{E}-05$ & 2.31E-04 & $\begin{array}{l}\text { COX7A1; NDUFB10; NDUFS1; } \\
\text { SDHB }\end{array}$ \\
\hline $\begin{array}{l}\text { Glycolysis/ } \\
\text { Gluconeogenesis }\end{array}$ & 414 & 4 & 64 & $3.51 \mathrm{E}-04$ & 0.001 & ALDH7A1; HK2; PKM2; TPI1 \\
\hline Metabolic pathways & 4373 & 15 & 1115 & 4.20E-04 & 0.001 & $\begin{array}{l}\text { ALDH7A1; ANPEP; ASAH1; } \\
\text { ATP6V1C1; ATP6V1H; HIBADH; } \\
\text { HK2; MGAM; NDUFB10; NDUFS1; } \\
\text { PGD; PKM2; SDHB; SUCLA2; TPI1 }\end{array}$ \\
\hline Galactose metabolism & 407 & 2 & 27 & 0.009 & 0.021 & HK2; MGAM \\
\hline Citrate cycle (TCA cycle) & 464 & 2 & 30 & 0.011 & 0.021 & SDHB; SUCLA2 \\
\hline Propanoate metabolism & 472 & 2 & 32 & 0.012 & 0.023 & ALDH7A1; SUCLA2 \\
\hline $\begin{array}{l}\text { Fructose and mannose } \\
\text { metabolism }\end{array}$ & 548 & 2 & 35 & 0.015 & 0.025 & HK2; TPI1 \\
\hline $\begin{array}{l}\text { Carbohydrate digestion } \\
\text { and absorption }\end{array}$ & 10389 & 2 & 41 & 0.020 & 0.031 & HK2; MGAM \\
\hline Pyruvate metabolism & 450 & 2 & 40 & 0.019 & 0.031 & ALDH7A1; PKM2 \\
\hline $\begin{array}{l}\text { Valine, leucine and } \\
\text { isoleucine degradation }\end{array}$ & 453 & 2 & 44 & 0.023 & 0.034 & ALDH7A1; HIBADH \\
\hline $\begin{array}{l}\text { Amino sugar and } \\
\text { nucleotide sugar } \\
\text { metabolism }\end{array}$ & 466 & 2 & 48 & 0.027 & 0.035 & $\mathrm{CHIT} 1 ; \mathrm{HK} 2$ \\
\hline $\begin{array}{l}\text { Glutathione } \\
\text { metabolism }\end{array}$ & 534 & 2 & 48 & 0.027 & 0.035 & ANPEP; PGD \\
\hline $\begin{array}{l}\text { Starch and sucrose } \\
\text { metabolism }\end{array}$ & 536 & 2 & 49 & 0.028 & 0.036 & HK2; MGAM \\
\hline $\begin{array}{l}\text { Epithelial cell signaling } \\
\text { in infection }\end{array}$ & 420 & 2 & 54 & 0.033 & 0.040 & ATP6V1C1; ATP6V1H \\
\hline RNA transport & 10361 & 3 & 149 & 0.044 & 0.052 & EIF3E; EIF3I; PABPC1 \\
\hline RNA degradation & 5710 & 2 & 68 & 0.050 & 0.056 & HSPD1; PABPC1 \\
\hline Lysosome & 4356 & 2 & 121 & 0.135 & 0.143 & ASAH1; ATP6V1H \\
\hline Phagosome & 10394 & 2 & 145 & 0.180 & 0.187 & ATP6V1C1; ATP6V1H \\
\hline
\end{tabular}

${ }^{a}$ Data from Table 1 were utilized to run a hypergeometric algorithm following a Benjamini-Hochberg correction for significance. Pathways not relevant to mosquito metabolism were deleted from the analysis

pyruvate metabolism, glycolysis), and infection (epithelial response and phagocytosis).

\section{Discussion}

P38 MAPK is an evolutionarily conserved signaling protein with critical activity for innate immunity, intermediary metabolism, and mitochondrial function. In mammals, PAMP induction of Toll-like receptor (TLR) signaling activates p38 MAPK, JNK, and NF-kBdependent transcription for the generation of distinct pro-inflammatory cytokines and cellular responses [91]. In Drosophila, p38 MAPK contributes to the regulation of the immune effectors through the Toll- or immune deficient (IMD)-independent pathways [19]. In C. elegans, vestiges of insect and mammalian Toll/TLR signaling are evident, but the nematode genome does not encode orthologs of MyD88, NF-kB, or IMD, suggesting that p38 MAPK signaling predates involvement of NF- $\mathrm{kB}$ in immunity [21]. However, p38 MAPK does not always positively regulate immune effector genes, but rather seems to modulate the quality and quantity of these effectors. In p38b mutant $D$. melanogaster, some genes encoding immune effectors and AMPs were up-regulated while some were down-regulated [20]. Our data suggested similar complexity in that AsP38 MAPK positively regulated Defensin1 gene promoter activity under LPS stimulation, negatively regulated $\mathrm{Cec}$ gene promoter activity for both LPS and PGN stimulation, and did not alter the regulation 
of Gam promoter activity under either immune stimulus in haemocyte-like ASE cells in vitro (Fig. 5). In the midgut epithelium, AsP38 MAPK negatively regulated a suite of known anti-parasite effector genes to varying degrees, but positively regulated $D E F 1$ gene expression in the same tissue (Fig. 6). Our results are consistent with p38 MAPK regulation of Def in A. aegypti [23] and for Cec in Aedes albopictus and D. melanogaster [20, 25].

In addition to immunity, p38 MAPK signaling is central to metabolic regulation and redox homeostasis. In this context, the principal mediators in mammals include PGC- $1 \alpha$ and PGC-1 $\beta$. In particular, activated p38 MAPK regulates expression of PGC-1 orthologs and can also directly phosphorylate substrates to modulate protein stability and activity [92-95]. Our data showed that p38 MAPK inhibition reduced PGC-1 midgut transcript levels in P. falciparum-infected A. stephensi (Fig. 9), which together with our biochemical and proteomics data (Fig. 10, Table 1), suggest that AsP38 MAPK-dependent regulation of PGC1 controls midgut glucose utilization via mitochondria. In mammalian liver, PGC- $1 \alpha$ and PGC- $1 \beta$ coordinately regulate gluconeogenesis and glycolysis in response to different stimuli (reviewed in [49]), and are largely redundant in the regulation of mitochondrial oxidative metabolism through coactivation of the peroxisome proliferator-activated receptors [50, 51], oestrogen-related receptors [52], and nuclear respiratory factors [53]. Intriguingly, however, the biological role of the relatively more ancient mammalian PGC-1 $\beta$ [95] appears to be reflected in A. stephensi. That is, inhibition of AsP38 MAPK downregulated midgut glycolysis and, more so, OXPHOS as judged by a decrease in hexokinase and PK proteins at $24 \mathrm{~h}$ post-treatment that was followed by a decrease in pyruvate by $48 \mathrm{~h}$ and an increase in lactate from pyruvate by $72 \mathrm{~h}$ (Fig. 10). In another context, PGC-1 $\beta$ control of mammalian NF- $\mathrm{kB}$ expression and activity suggests that a similar metabolic-immune signaling axis is mediated by PGC- 1 that complements mitochondrial ATP and ROS-mediated gene activation in the $A$. stephensi midgut (Fig. 8).

Inhibition of AsP38 MAPK resulted in increased levels of midgut mitochondrial superoxide and stress-induced peroxide at $6 \mathrm{~h}$ following provision of BIRB796 in a saline meal (Fig. 7a, b and c) that are likely sustained through at least $24 \mathrm{~h}$ following $P$. falciparum infection by reduced levels of SOD2 and catalase (Table 1). This increase in steady-state concentrations of midgut ROS that cannot be mitigated by endogenous antioxidants likely contributes to reduced short-term survivorship of A. stephensi relative to controls (Fig. 7d). Similar observations in both mammals and in D. melanogaster suggest that p38 MAPK regulation of antioxidants is critical for cellular response to oxidative stress. In particular, inhibition of p38 $\alpha$ in mouse embryonic fibroblasts led to ROS accumulation upon exposure to hydrogen peroxide, significantly increasing cell death that could be rescued with antioxidant treatment [40]. In D. melanogaster, p38b and $\mathrm{p} 38 \mathrm{a} / \mathrm{b}$ double mutants exhibited significantly decreased short-term survival to continuous feeding with hydrogen peroxide compared to wild type controls [38]. Further, the more extensive effects of shortened lifespans observed in p38b mutants and p38a/b double mutants could be rescued by overexpression of p38b [38], suggesting that p38 MAPK-dependent signaling is critical for both short-term protection against oxidative stress and longer term survival. Intriguingly, PGC-1 $\alpha$ is required for the induction of antioxidants (SOD1, SOD2, catalase, GPx1) to suppress ROS levels in mice in vivo and in murine neuronal cells in vitro [96], suggesting that a lack of PGC-1 activity in fruit flies and mosquitoes could also explain the effects of p38 MAPK inhibition on sensitivity to oxidative stress.

Bacteria present in the midgut have been shown to modulate the mosquito immune response through activation of basal immunity and in the absence of midgut flora Anopheles mosquitoes are more susceptible to Plasmodium infection [97]. Although blood feeding leads to a bloom of gut microflora in Anopheles [98-100], it also concurrently reduces the diversity of the gut bacterial community dramatically [100]. Therefore, while it is likely that midgut bacteria contribute to p38 MAPK activation during blood feeding, our data suggest that this effect is altered by the presence of malaria parasites. In particular, we have shown that there are no significant differences in midgut bacteria CFUs in mosquitoes fed uninfected versus Plasmodium-infected blood either at 24 or $48 \mathrm{~h}$ post feeding (Additional file 2). Therefore, we can infer that the contribution of bacteria and endotoxin to the observed changes in AsP38 MAPK signaling are consistent between mosquitoes fed uninfected and infected blood. As such, any differences observed in mosquitoes fed an infectious blood meal are due to the presence of parasites and not to quantitative alterations in midgut flora. Interestingly, infected RBCs have been shown to contain endotoxin-like lipidic molecules [101] and could, therefore, activate p38 MAPK signaling via pathways that are similar to those activated by bacterial endotoxin.

In mammals, p38 MAPK activation has been associated with increased mRNA translation via phosphorylation of MK2, which enhances mRNA stability and translation $[47,90]$. Inhibition of $A s$ P38 MAPK was associated with reduced phosphorylation of MK2 in ASE cells and in the midgut epithelium (Fig. 3) and with significantly reduced levels of proteins associated with mRNA translation in the same tissue at $24 \mathrm{~h}$ posttreatment (Table 1). A previous study reported significantly enhanced translation of midgut mRNAs during the first 22-26 h following $P$. falciparum infection in $A$. gambiae with notably few changes in mRNAs for immune genes [102], suggesting that parasite-induced 
activation of p38 MAPK signaling in the midgut epithelium of both important malaria vectors regulates a conserved response to infection. Alternatively, compromised ATP status emerging from lower glucose catabolism can also decrease the high-energy consuming process of synthesizing ribosomal RNAs. Based on data from Fig. 10, the ATP generated following treatment with BIRB796 can be estimated as $44 \%$ of controls, conditions akin to starvation that may also decrease protein synthesis as evidenced by the 5 -fold ratio of underrepresented/overrepresented proteins (Table 1).

\section{Conclusions}

In this study, we used small molecule inhibitors as tools to probe the significance of parasite infection-induced AsP38 MAPK phosphorylation and infer that this activation induces PGC-1 expression, which contributes to increased glycolysis, mitochondrial biogenesis, and synthesis of

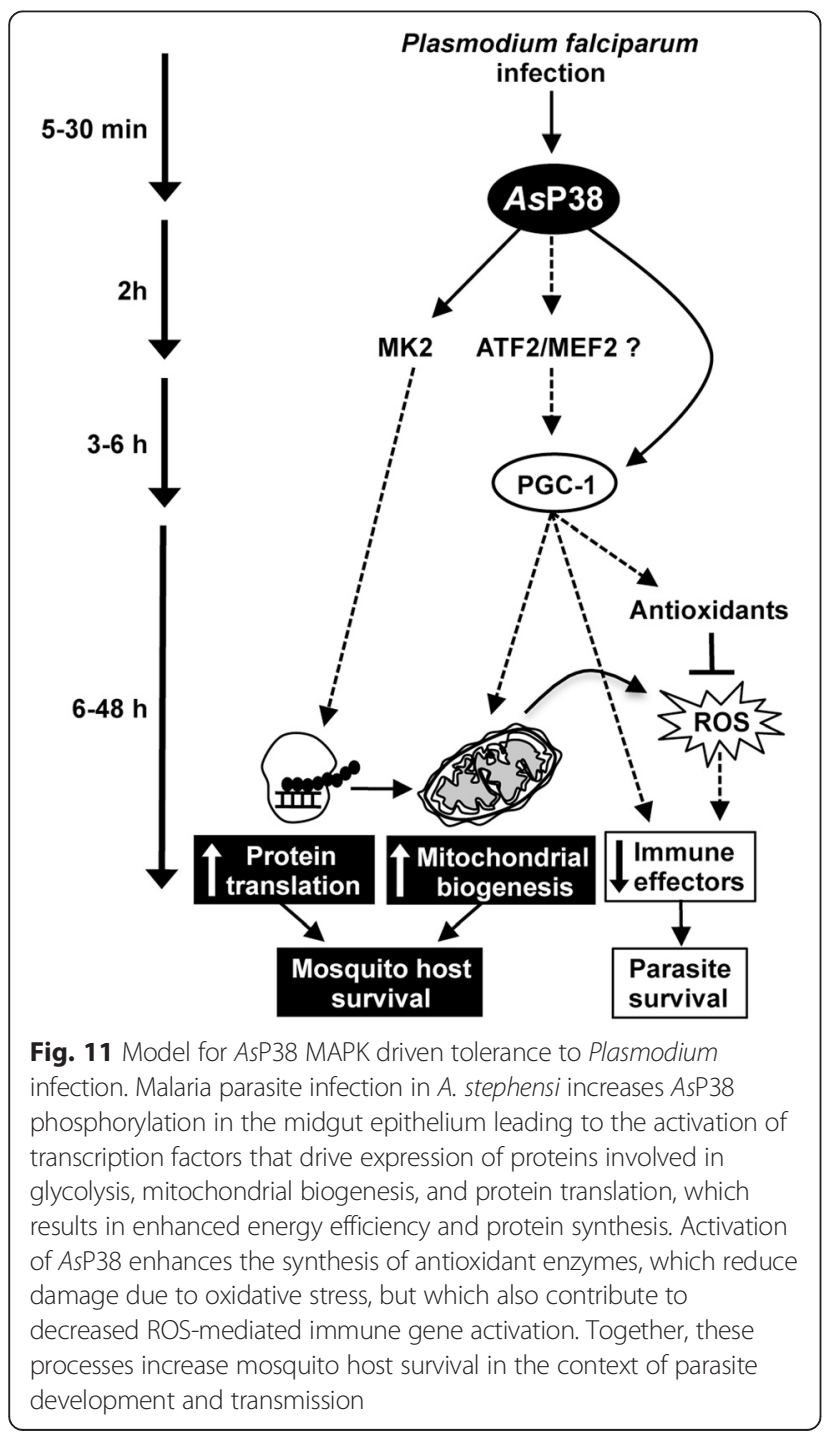

antioxidant enzymes. Further, AsP38 MAPK activation enhances MK2 phosphorylation and, as interpreted from BIRB796 inhibition, mRNA translation in the midgut epithelium, events that are likely to be functionally connected. Hence, parasite-mediated activation of p38 MAPK signaling in the $A$. stephensi midgut likely protects the host from oxidative stress and enhances survivorship, but also decreases the activation of energetically costly antiparasite gene expression. Increased glycolysis, OXPHOS and mRNA translation can mitigate energy loss and cellular damage due to infection (Fig. 11), suggesting that AsP38 MAPK signaling contributes to mosquito survival during $P$. falciparum infection.

Our data have revealed that p38 MAPK activation during P. falciparum infection of $A$. stephensi is associated with enhanced fitness - as defined by increased protein synthesis, mitochondrial biogenesis, and resistance to oxidative stress- and a reduced innate immune response to infection. Given that insecticide resistance has been associated with enhanced mitochondrial metabolism (Complexes I and IV; [103]) and antioxidant levels (GST, TPX2; [103, 104]), genetic or pharmacological strategies to inhibit p38 MAPK signaling in natural populations of mosquitoes could decrease malaria parasite infection prevalence and enhance acute susceptibility to chemical pesticides. Together with our previous work [63], these data provide additional evidence for networked regulation of mitochondrial metabolism, antioxidant response and immunity in A. stephensi, which can be leveraged for improved methods for malaria transmission control.

\section{Additional files}

Additional file 1: $P$. falciparum parasite products (PfPs) induced AsP38 MAPK phosphorylation in vitro relative to control. (TIFF $1850 \mathrm{~kb}$ )

Additional file 2: $P$. falciparum-infected RBCs did not significantly alter midgut bacterial growth relative to uninfected RBCs. (TIFF $2079 \mathrm{~kb}$ )

\section{Abbreviations}

ASE: A. stephensi embryonic; AsP38: A. stephensi p38; BLAST: Basic Local Alignment Search Tool; ERK: Extracellular signal-regulated kinase; JNK: c-Jun N-terminal kinases; G6Pase: glucose-6-phosphatase; FTPP: Freeze-thawed $P$. falciparum products; IMD: Immune deficient; IIS: Insulin/insulin-like growth factor signaling; TOR: Insulin-target of rapamycin; IFN-y: Interferon; LC-MS/ MS: Liquid chromatography/tandem mass spectrometry; MAPK: Mitogenactivated protein kinase; MK2: MAPK-activated kinase 2; NF-KB: Nuclear factor; OXPHOS: Oxidative phosphorylation; PAMPs: Pathogen-associated molecular patterns; PGC-1a: Peroxisome proliferator-activated receptor gamma coactivator-1a; PGN: Peptidoglycan; PEPCK: Phosphoenolpyruvate carboxykinase; PK: Pyruvate kinase; RNOS: Reactive nitrogen and oxygen species; (ROS): Reactive oxygen species; RBCs: Red blood cells; TLR: Toll-like receptor; STAT-1: Signal transducer and activator of transcription; (SOD2): Superoxide dismutase.

\section{Competing interests}

The authors declare that they have no competing interests. 


\section{Authors' contributions}

Conceived and designed the experiments: BW CG SL. Performed the experiments: BW NP EN AD EG WS KC AA JMK RE BSP. Analysed the data: BW NP EN AD WS RE BSP CG SL. Wrote the paper: BW NP CG SL. All authors read and approved the final version of the manuscript.

\section{Acknowledgments}

Funding was provided by NIH NIAID AI080799, Al073745, and Al107263.

\section{Author details}

'Department of Medical Microbiology and Immunology, School of Medicine, University of California Davis, 3437 Tupper Hall, One Shields Avenue, Davis, CA 95616, USA. ²Department of Molecular Biosciences, School of Veterinary Medicine, University of California Davis, Davis, CA, USA. ${ }^{3}$ Department of Entomology and Nematology, University of California Davis, Davis, CA, USA. ${ }^{4}$ Genome and Biomedical Sciences Center, University of California Davis, Davis, CA, USA. ${ }^{5}$ Medical Investigations of Neurodevelopmental Disorders (MIND) Institute, University of California Davis, Davis, CA, USA.

Received: 29 April 2015 Accepted: 21 July 2015

\section{Published online: 19 August 2015}

\section{References}

1. WHO. World Malaria Report 2014. Geneva: World Health Organization; 2014.

2. Clayton AM, Dong Y, Dimopoulos G. The Anopheles innate immune system in the defense against malaria infection. J Innate Immun. 2014;6(2):169-81. doi:10.1159/000353602

3. Whitten MM, Shiao SH, Levashina EA. Mosquito midguts and malaria: cell biology, compartmentalization and immunology. Parasite Immunol. 2006;28(4):121-30. doi:10.1111/j.1365-3024.2006.00804.x.

4. Baton LA, Ranford-Cartwright LC. Ookinete destruction within the mosquito midgut lumen explains Anopheles albimanus refractoriness to Plasmodium falciparum (3D7A) oocyst infection. International J Parasitol. 2012;42(3):249-58. doi:10.1016/j.ijpara.2011.12.005.

5. Lim J, Gowda DC, Krishnegowda G, Luckhart S. Induction of nitric oxide synthase in Anopheles stephensi by Plasmodium falciparum: mechanism of signaling and the role of parasite glycosylphosphatidylinositols. Infect Immun. 2005:73(5):2778-89. doi:10.1128/IAl.73.5.2778-2789.2005.

6. Luckhart S, Vodovotz Y, Cui L, Rosenberg R. The mosquito Anopheles stephensi limits malaria parasite development with inducible synthesis of nitric oxide. Proc Natl Acad Sci U S A. 1998;95(10):5700-5.

7. Pakpour N, Camp L, Smithers HM, Wang B, Tu Z, Nadler SA, et al. Protein kinase C-dependent signaling controls the midgut epithelial barrier to malaria parasite infection in anopheline mosquitoes. Plos One. 2013;8(10):e76535.

8. Peterson TM, Gow AJ, Luckhart S. Nitric oxide metabolites induced in Anopheles stephensi control malaria parasite infection. Free Rad Biol Med. 2007;42(1):132-42. doi:10.1016/j.freeradbiomed.2006.10.037.

9. Surachetpong W, Singh N, Cheung KW, Luckhart S. MAPK ERK signaling regulates the TGF-beta1-dependent mosquito response to Plasmodium falciparum. PLoS Pathog. 2009;5(4):e1000366. doi:10.1371/ journal.ppat.1000366.

10. Blandin S, Moita LF, Kocher T, Wilm M, Kafatos FC, Levashina EA. Reverse genetics in the mosquito Anopheles gambiae: targeted disruption of the Defensin gene. EMBO Rep. 2002;3(9):852-6. doi:10.1093/embo-reports/kvf180.

11. Povelones M, Waterhouse RM, Kafatos FC, Christophides GK. Leucinerich repeat protein complex activates mosquito complement in defense against Plasmodium parasites. Science. 2009;324(5924):258-61. doi:10.1126/science.1171400.

12. Mitri C, Jacques JC, Thiery I, Riehle MM, Xu J, Bischoff E, et al. Fine pathogen discrimination within the APL1 gene family protects Anopheles gambiae against human and rodent malaria species. PLoS Pathog. 2009;5(9):e1000576. doi:10.1371/journal.ppat.1000576.

13. Riehle MM, Markianos K, Niare O, Xu J, Li J, Toure AM, et al. Natural malaria infection in Anopheles gambiae is regulated by a single genomic control region. Science. 2006;312(5773):577-9. doi:10.1126/science.1124153.

14. Osta MA, Christophides GK, Kafatos FC. Effects of mosquito genes on Plasmodium development. Science. 2004;303(5666):2030-2. doi:10.1126/ science.1091789.
15. Dong Y, Aguilar R, Xi Z, Warr E, Mongin E, Dimopoulos G. Anopheles gambiae immune responses to human and rodent Plasmodium parasite species. PLoS Pathog. 2006;2(6):e52. doi:10.1371/journal.ppat.0020052.

16. Vlachou D, Zimmermann T, Cantera R, Janse CJ, Waters AP, Kafatos FC. Realtime, in vivo analysis of malaria ookinete locomotion and mosquito midgut invasion. Cell Microbiol. 2004;6(7):671-85. doi:10.1111/j.1462-5822.2004.00394.x.

17. Dong C, Davis RJ, Flavell RA. MAP kinases in the immune response. Annual Rev Immunol. 2002:20:55-72. doi:10.1146/annurev.immunol.20.091301.131133.

18. Akira S, Uematsu S, Takeuchi O. Pathogen recognition and innate immunity. Cell. 2006;124(4):783-801. doi:10.1016/j.cell.2006.02.015.

19. Chen J, Xie C, Tian L, Hong L, Wu X, Han J. Participation of the p38 pathway in Drosophila host defense against pathogenic bacteria and fungi. Proc Natl Acad Sci U S A. 2010;107(48):20774-9. doi:10.1073/pnas.1009223107.

20. Han ZS, Enslen H, Hu X, Meng X, Wu IH, Barrett T, et al. A conserved p38 mitogen-activated protein kinase pathway regulates Drosophila immunity gene expression. Molec Cell Biol. 1998;18(6):3527-39.

21. Kim DH, Feinbaum R, Alloing G, Emerson FE, Garsin DA, Inoue H, et al. A conserved p38 MAP kinase pathway in Caenorhabditis elegans innate immunity. Science. 2002;297(5581):623-6. doi:10.1126/science.1073759.

22. Ono K, Han J. The p38 signal transduction pathway: activation and function. Cell Signal. 2000;12(1):1-13

23. Chen-Chih Wu R, Shaio MF, Cho WL. A p38 MAP kinase regulates the expression of the Aedes aegypti defensin gene in mosquito cells. Insect Molec Biol. 2007;16(4):389-99. doi:10.1111/j.1365-2583.2007.00734.x.

24. Cancino-Rodezno A, Alexander C, Villasenor R, Pacheco S, Porta H, Pauchet $Y$, et al. The mitogen-activated protein kinase p38 is involved in insect defense against Cry toxins from Bacillus thuringiensis. Insect Biochem Mol Biol. 2010;40(1):58-63. doi:10.1016/j.ibmb.2009.12.010.

25. Moon AE, Walker AJ, Goodbourn S. Regulation of transcription of the Aedes albopictus cecropin A1 gene: A role for p38 mitogen-activated protein kinase. Insect Biochem Mol Biol. 2011;41(8):628-36. doi:10.1016/ j.ibmb.2011.04.001.

26. Ha EM, Lee KA, Seo YY, Kim SH, Lim JH, Oh BH, et al. Coordination of multiple dual oxidase-regulatory pathways in responses to commensal and infectious microbes in Drosophila gut. Nat Immunol. 2009;10(9):949-57. doi:10.1038/ni.1765.

27. Park JS, Kim YS, Yoo MA. The role of p38b MAPK in age-related modulation of intestinal stem cell proliferation and differentiation in Drosophila. Aging (Albany NY). 2009;1 (7):637-51

28. Park JS, Kim YS, Kim JG, Lee SH, Park SY, Yamaguchi M, et al. Regulation of the Drosophila p38b gene by transcription factor DREF in the adult midgut. Biochim Biophys Acta. 2010;1799(7):510-9. doi:10.1016/j.bbagrm.2010.03.001.

29. Troemel ER, Chu SW, Reinke V, Lee SS, Ausubel FM, Kim DH. p38 MAPK regulates expression of immune response genes and contributes to longevity in C. elegans. PLoS Genet. 2006;2(11):e183. doi:10.1371/journal.pgen.0020183.

30. Hoeven R, McCallum KC, Cruz MR, Garsin DA. Ce-Duox1/BLI-3 generated reactive oxygen species trigger protective SKN-1 activity via p38 MAPK signaling during infection in C. elegans. PLoS Pathog. 2011;7(12):e1002453. doi:10.1371/journal.ppat.1002453.

31. Horton AA, Wang B, Camp L, Price MS, Arshi A, Nagy M, et al. The mitogenactivated protein kinome from Anopheles gambiae: identification, phylogeny and functional characterization of the ERK, JNK and p38 MAP kinases. BMC Genomics. 2011;12:574. doi:10.1186/1471-2164-12-574.

32. Vodovotz YAN, Miskov-Zivanov N, Buliga M, Zamora R, Ermentrout B, Constantine GM, et al. Modeling Host-Vector-Pathogen Immunoinflammatory Interactions in Malaria. In: Vodovotz YAG, editor. Complex Systems and Computational Biology Approaches to Acute Inflammation. New York: Springer Science + Business Media; 2013. p. 291.

33. Matsuzawa A, Ichijo H. Redox control of cell fate by MAP kinase: physiological roles of ASK1-MAP kinase pathway in stress signaling. Biochim Biophys Acta. 2008;1780(11):1325-36. doi:10.1016/j.bbagen.2007.12.011.

34. Kyriakis JM, Avruch J. Mammalian mitogen-activated protein kinase signal transduction pathways activated by stress and inflammation. Physiol Rev. 2001;81(2):807-69

35. Surachetpong W, Pakpour N, Cheung KW, Luckhart S. Reactive oxygen species-dependent cell signaling regulates the mosquito immune response to Plasmodium falciparum. Antiox Redox Signal. 2011;14(6):943-55. doi:10.1089/ars.2010.3401.

36. Son Y, Kim S, Chung HT, Pae HO. Reactive oxygen species in the activation of MAP kinases. Methods Enzymol. 2013;528:27-48. doi:10.1016/B978-0-12-405881-1.00002-1. 
37. Shinzawa N, Nelson B, Aonuma H, Okado K, Fukumoto S, Miura M, et al. p38 MAPK-dependent phagocytic encapsulation confers infection tolerance in Drosophila. Cell Host Microbe. 2009;6(3):244-52. doi:10.1016/ j.chom.2009.07.010

38. Vrailas-Mortimer A, del Rivero T, Mukherjee S, Nag S, Gaitanidis A, Kadas D, et al. A muscle-specific p38 MAPK/Mef2/MnSOD pathway regulates stress, motor function, and life span in Drosophila. Dev Cell. 2011;21(4):783-95. doi:10.1016/j.devcel.2011.09.002

39. Gostner JM, Becker K, Fuchs D, Sucher R. Redox regulation of the immune response. Redox Rep. 2013;18(3):88-94. doi:10.1179/1351000213Y.0000000044

40. Gutierrez-Uzquiza A, Arechederra M, Bragado P, Aguirre-Ghiso JA, Porras A. p38alpha mediates cell survival in response to oxidative stress via induction of antioxidant genes: effect on the p70S6K pathway. J Biol Chem. 2012;287(4):2632-42. doi:10.1074/jbc.M111.323709.

41. Molina-Cruz A, DeJong RJ, Charles B, Gupta L, Kumar S, Jaramillo-Gutierrez $G$, et al. Reactive oxygen species modulate Anopheles gambiae immunity against bacteria and Plasmodium. J Biol Chem. 2008;283(6):3217-23. doi:10.1074/jbc.M705873200.

42. Lanz-Mendoza H, Hernandez-Martinez S, Ku-Lopez M, Rodriguez Mdel C, Herrera-Ortiz A, Rodriguez MH. Superoxide anion in Anopheles albimanus hemolymph and midgut is toxic to Plasmodium berghei ookinetes. J Parasitol. 2002:88(4):702-6. doi:10.1645/0022-3395(2002)088[0702-SAIAAH]2.0.CO:2.

43. Brune B, Dehne N, Grossmann N, Jung M, Namgaladze D, Schmid T, et al. Redox control of inflammation in macrophages. Antioxid Redox Signal. 2013;19(6):595-637. doi:10.1089/ars.2012.4785.

44. Gloire G, Legrand-Poels S, Piette J. NF-kappaB activation by reactive oxygen species: fifteen years later. Biochem Pharmacol. 2006;72(11):1493-505. doi:10.1016/j.bcp.2006.04.011.

45. Shaw G, Kamen R. A conserved AU sequence from the 3' untranslated region of GM-CSF mRNA mediates selective mRNA degradation. Cell. 1986:46(5):659-67.

46. Shyu AB, Greenberg ME, Belasco JG. The c-fos transcript is targeted for rapid decay by two distinct mRNA degradation pathways. Genes Dev. 1989;3(1):60-72

47. Tiedje C, Ronkina N, Tehrani M, Dhamija S, Laass K, Holtmann H, et al. The p38/MK2-driven exchange between tristetraprolin and HuR regulates AU-rich element-dependent translation. PLoS Genet. 2012;8(9):e1002977. doi:10.1371/journal.pgen.1002977.

48. Winzen $R$, Kracht $M$, Ritter B, Wilhelm A, Chen CY, Shyu AB, et al. The p38 MAP kinase pathway signals for cytokine-induced mRNA stabilization via MAP kinase-activated protein kinase 2 and an AU-rich region-targeted mechanism. EMBO J. 1999;18(18):4969-80. doi:10.1093/emboj/18.18.4969.

49. Lin J, Handschin C, Spiegelman BM. Metabolic control through the PGC-1 family of transcription coactivators. Cell Metab. 2005;1(6):361-70. doi:10.1016/j.cmet.2005.05.004.

50. Lai L, Leone TC, Zechner C, Schaeffer PJ, Kelly SM, Flanagan DP, et al. Transcriptional coactivators PGC-1alpha and PGC-Ibeta control overlapping programs required for perinatal maturation of the heart. Genes Dev. 2008;22(14):1948-61. doi:10.1101/gad.1661708.

51. Puigserver P, Wu Z, Park CW, Graves R, Wright M, Spiegelman BM. A coldinducible coactivator of nuclear receptors linked to adaptive thermogenesis. Cell. 1998:92(6):829-39.

52. Huss JM, Kopp RP, Kelly DP. Peroxisome proliferator-activated receptor coactivator-1alpha (PGC-1alpha) coactivates the cardiac-enriched nuclear receptors estrogen-related receptor-alpha and-gamma. Identification of novel leucine-rich interaction motif within PGC-1alpha. J Biol Chem. 2002:277(43):40265-74. doi:10.1074/jbc.M206324200.

53. Wu Z, Puigserver $P$, Andersson U, Zhang C, Adelmant G, Mootha $V$, et al. Mechanisms controlling mitochondrial biogenesis and respiration through the thermogenic coactivator PGC-1. Cell. 1999;98(1):115-24. doi:10.1016/S0092-8674(00)80611-X.

54. Chambers KT, Chen Z, Lai L, Leone TC, Towle HC, Kralli A, et al. PGC-1beta and ChREBP partner to cooperatively regulate hepatic lipogenesis in a glucose concentration-dependent manner. Molec Metab. 2013;2(3):194-204. doi:10.1016/j.molmet.2013.05.001.

55. Yoon JC, Puigserver P, Chen G, Donovan J, Wu Z, Rhee J, et al. Control of hepatic gluconeogenesis through the transcriptional coactivator PGC-1. Nature. 2001;413(6852):131-8. doi:10.1038/35093050.

56. Herzig S, Long F, Jhala US, Hedrick S, Quinn R, Bauer A, et al. CREB regulates hepatic gluconeogenesis through the coactivator PGC-1. Nature. 2001;413(6852):179-83. doi:10.1038/35093131.
57. Lin J, Yang R, Tarr PT, Wu PH, Handschin C, Li S, et al. Hyperlipidemic effects of dietary saturated fats mediated through PGC-1 beta coactivation of SREBP. Cell. 2005;120(2):261-73. doi:10.1016/j.cell.2004.11.043.

58. Sonoda J, Laganiere J, Mehl IR, Barish GD, Chong LW, Li X, et al. Nuclear receptor ERR alpha and coactivator PGC-1 beta are effectors of IFN-gammainduced host defense. Genes Dev. 2007;21(15):1909-20. doi:10.1101/ gad.1553007.

59. Vats D, Mukundan L, Odegaard JI, Zhang L, Smith KL, Morel CR, et al. Oxidative metabolism and PGC-1 beta attenuate macrophage-mediated inflammation. Cell Metab. 2006;4(1):13-24. doi:10.1016/ j.cmet.2006.05.011.

60. Tiefenbock SK, Baltzer C, Egli NA, Frei C. The Drosophila PGC-1 homologue Spargel coordinates mitochondrial activity to insulin signalling. EMBO J. 2010;29(1):171-83. doi:10.1038/emboj.2009.330.

61. Rera M, Bahadorani S, Cho J, Koehler CL, Ulgherait M, Hur JH, et al. Modulation of longevity and tissue homeostasis by the Drosophila PGC-1 homolog. Cell Metab. 2011;14(5):623-34. doi:10.1016/j.cmet.2011.09.013.

62. Mukherjee S, Duttaroy A. Spargel/dPGC-1 is a new downstream effector in the insulin-TOR signaling pathway in Drosophila. Genetics. 2013;195(2):433-41. doi:10.1534/genetics.113.154583.

63. Luckhart S, Giulivi C, Drexler AL, Antonova-Koch Y, Sakaguchi D, Napoli E, et al. Sustained activation of Akt elicits mitochondrial dysfunction to block Plasmodium falciparum infection in the mosquito host. PLoS Pathog. 2013;9(2):e1003180. doi:10.1371/journal.ppat.1003180.

64. Altschul SF, Gish W, Miller W, Myers EW, Lipman DJ. Basic local alignment search tool. J Molecular Biol. 1990;215(3):403-10. doi:10.1016/S00222836(05)80360-2.

65. Kozak M. Compilation and analysis of sequences upstream from the translational start site in eukaryotic mRNAs. Nuc Acids Res. 1984;12(2):857-72.

66. Pakpour N, Corby-Harris V, Green GP, Smithers HM, Cheung KW, Riehle MA et al. Ingested human insulin inhibits the mosquito NF-kappaB-dependent immune response to Plasmodium falciparum. Infect Immun. 2012;80(6):2141-9. doi:10.1128/IAl.00024-12.

67. Lambros C, Vanderberg JP. Synchronization of Plasmodium falciparum erythrocytic stages in culture. J Parasitol. 1979;65(3):418-20.

68. Hauck ES, Antonova-Koch Y, Drexler A, Pietri J, Pakpour N, Liu D, et al. Overexpression of phosphatase and tensin homolog improves fitness and decreases Plasmodium falciparum development in Anopheles stephensi. Microbes Infect. 2013;15(12):775-87. doi:10.1016/ j.micinf.2013.05.006

69. Keller A, Nesvizhskii Al, Kolker E, Aebersold R. Empirical statistical model to estimate the accuracy of peptide identifications made by MS/MS and database search. Anal Chem. 2002;74(20):5383-92.

70. Nesvizhskii Al, Keller A, Kolker E, Aebersold R. A statistical model for identifying proteins by tandem mass spectrometry. Anal Chem. 2003;75(17):4646-58.

71. Tabb DL. What's driving false discovery rates? J Proteome Res. 2008;7(1):45-6. doi:10.1021/pr700728t.

72. Schneider CA, Rasband WS, Eliceiri KW. NIH Image to ImageJ: 25 years of image analysis. Nat Meth. 2012:9(7):671-5.

73. Beutler E. Red cell metabolism : a manual of biochemical methods. 3rd ed Orlando, FL: Grune \& Stratton; 1984

74. Giulivi C, Zhang YF, Omanska-Klusek A, Ross-Inta C, Wong S, Hertz-Picciotto I, et al. Mitochondrial dysfunction in autism. JAMA. 2010:304(21):2389-96. doi:10.1001/jama.2010.1706.

75. Zhang J, Shen B, Lin A. Novel strategies for inhibition of the p38 MAPK pathway. Trends Pharmacol Sci. 2007:28(6):286-95. doi:10.1016/j.tips.2007.04.008.

76. Cuenda A, Rouse J, Doza YN, Meier R, Cohen P, Gallagher TF, et al. SB 203580 is a specific inhibitor of a MAP kinase homologue which is stimulated by cellular stresses and interleukin-1. FEBS Lett. 1995:364(2):229-33.

77. Kuma Y, Sabio G, Bain J, Shpiro N, Marquez R, Cuenda A. BIRB796 inhibits all p38 MAPK isoforms in vitro and in vivo. J Biol Chem. 2005;280(20):19472-9. doi:10.1074/jbc.M414221200.

78. Pargellis $C$, Tong $L$, Churchill $L$, Cirillo PF, Gilmore T, Graham AG, et al. Inhibition of p38 MAP kinase by utilizing a novel allosteric binding site. Nat Struc Biol. 2002;9(4):268-72. doi:10.1038/nsb770.

79. Wilson KP, Fitzgibbon MJ, Caron PR, Griffith JP, Chen W, McCaffrey PG, et al. Crystal structure of p38 mitogen-activated protein kinase. J Biol Chem. 1996;271(44):27696-700 
80. Wood CD, Thornton TM, Sabio G, Davis RA, Rincon M. Nuclear localization of p38 MAPK in response to DNA damage. Intl J Biol Sci. 2009;5(5):428-37.

81. Dorin-Semblat D, Quashie N, Halbert J, Sicard A, Doerig C, Peat E, et al Functional characterization of both MAP kinases of the human malaria parasite Plasmodium falciparum by reverse genetics. Molec Microbiol. 2007;65(5):1170-80. doi:10.1111/j.1365-2958.2007.05859.x.

82. Brumlik MJ, Nkhoma S, Kious MJ, Thompson 3rd GR, Patterson TF, Siekierka $\mathrm{J}$, et al. Human p38 mitogen-activated protein kinase inhibitor drugs inhibit Plasmodium falciparum replication. Exp Parasitol. 2011;128(2):170-5. doi:10.1016/j.exppara.2011.02.016.

83. Ashwell JD. The many paths to p38 mitogen-activated protein kinase activation in the immune system. Nat Rev Immunol. 2006;6(7):532-40. doi:10.1038/nri1865.

84. Roux PP, Blenis J. ERK and p38 MAPK-activated protein kinases: a family of protein kinases with diverse biological functions. Microbiol Molec Biol Rev. 2004:68(2):320-44. doi:10.1128/MMBR.68.2.320-344.2004

85. Figueira TR, Barros MH, Camargo AA, Castilho RF, Ferreira JC, Kowaltowski $\mathrm{AJ}$, et al. Mitochondria as a source of reactive oxygen and nitrogen species: from molecular mechanisms to human health. Antiox Redox Signal. 2013;18(16):2029-74. doi:10.1089/ars.2012.4729.

86. Ockenhouse CF, Shear HL. Oxidative killing of the intraerythrocytic malaria parasite Plasmodium yoelii by activated macrophages. J Immunol. 1984:132(1):424-31.

87. Dockrell HM, Playfair JH. Killing of blood-stage murine malaria parasites by hydrogen peroxide. Infect Immun. 1983;39(1):456-9.

88. Kumar S, Christophides GK, Cantera R, Charles B, Han YS, Meister S, et al. The role of reactive oxygen species on Plasmodium melanotic encapsulation in Anopheles gambiae. Proc Natl Acad Sci U S A. 2003;100(24):14139-44. doi:10.1073/pnas.2036262100

89. Drexler AL, Pietri JE, Pakpour N, Hauck E, Wang B, Glennon EK, et al. Human IGF1 regulates midgut oxidative stress and epithelial homeostasis to balance lifespan and Plasmodium falciparum resistance in Anopheles stephensi. PLoS Pathog. 2014;10(6):e1004231. doi:10.1371/ journal.ppat.1004231.

90. Venigalla RK, Turner M. RNA-binding proteins as a point of convergence of the PI3K and p38 MAPK pathways. Front Immunol. 2012;3:398. doi:10.3389/ fimmu.2012.00398.

91. Arthur JS, Ley SC. Mitogen-activated protein kinases in innate immunity. Nat Rev Immunol. 2013;13(9):679-92. doi:10.1038/nri3495.

92. Fernandez-Marcos PJ, Auwerx J. Regulation of PGC-1alpha, a nodal regulator of mitochondrial biogenesis. Am J Clin Nutr. 2011;93(4):884S-90. doi:10.3945/ajen.110.001917.

93. Puigserver $P$, Rhee J, Lin J, Wu Z, Yoon JC, Zhang CY, et al. Cytokine stimulation of energy expenditure through p38 MAP kinase activation of PPARgamma coactivator-1. Molec Cell. 2001;8(5):971-82.

94. Puigserver $P$, Spiegelman BM. Peroxisome proliferator-activated receptorgamma coactivator 1 alpha (PGC-1 alpha): transcriptional coactivator and metabolic regulator. Endocr Rev. 2003;24(1):78-90.

95. Xiong Y, Collins QF, An J, Lupo Jr E, Liu HY, Liu D, et al. p38 mitogenactivated protein kinase plays an inhibitory role in hepatic lipogenesis. J Biol Chem. 2007;282(7):4975-82. doi:10.1074/jbc.M606742200.

96. St-Pierre J, Drori S, Uldry M, Silvaggi JM, Rhee J, Jager S, et al. Suppression of reactive oxygen species and neurodegeneration by the PGC-1 transcriptional coactivators. Cell. 2006;127(2):397-408. doi:10.1016/ j.cell.2006.09.024

97. Dong Y, Manfredini F, Dimopoulos G. Implication of the mosquito midgut microbiota in the defense against malaria parasites. PLoS Pathog. 2009;5(5):e1000423. doi:10.1371/journal.ppat.1000423.

98. Gusmao DS, Santos AV, Marini DC, Bacci Jr M, Berbert-Molina MA, Lemos FJ. Culture-dependent and culture-independent characterization of microorganisms associated with Aedes aegypti (Diptera: Culicidae) (L.) and dynamics of bacterial colonization in the midgut. Acta Trop. 2010;115(3):275-81. doi:10.1016/j.actatropica.2010.04.011.

99. Pumpuni CB, Demaio J, Kent M, Davis JR, Beier JC. Bacterial population dynamics in three anopheline species: the impact on Plasmodium sporogonic development. Am J Trop Med Hyg. 1996:54(2):214-8.

100. Wang Y, Gilbreath 3rd TM, Kukutla P, Yan G, Xu J. Dynamic gut microbiome across life history of the malaria mosquito Anopheles gambiae in Kenya. PloS One. 2011;6(9):e24767. doi:10.1371/journal.pone.0024767.
101. Caro HN, Sheikh NA, Taverne J, Playfair JH, Rademacher TW. Structural similarities among malaria toxins insulin second messengers, and bacterial endotoxin. Infect Immun. 1996;64(8):3438-41.

102. Mead EA, Li M, Tu Z, Zhu J. Translational regulation of Anopheles gambiae mRNAs in the midgut during Plasmodium falciparum infection. BMC Genomics. 2012;13:366. doi:10.1186/1471-2164-13-366.

103. Zhu G, Zhong D, Cao J, Zhou H, Li J, Liu Y, et al. Transcriptome profiling of pyrethroid resistant and susceptible mosquitoes in the malaria vector, Anopheles sinensis. BMC Genomics. 2014;15:448. doi:10.1186/ 1471-2164-15-448.

104. Fossog Tene B, Poupardin R, Costantini C, Awono-Ambene P, Wondji CS, Ranson $\mathrm{H}$, et al. Resistance to DDT in an urban setting: common mechanisms implicated in both $\mathrm{M}$ and $\mathrm{S}$ forms of Anopheles gambiae in the city of Yaounde Cameroon. PloS One. 2013;8(4):e61408. doi:10.1371/ journal.pone.0061408.

\section{Submit your next manuscript to BioMed Central and take full advantage of:}

- Convenient online submission

- Thorough peer review

- No space constraints or color figure charges

- Immediate publication on acceptance

- Inclusion in PubMed, CAS, Scopus and Google Scholar

- Research which is freely available for redistribution 